\title{
AN ENERGY INTEGRATED APPROACH TO DESIGN SUPERCRITICAL FISCHER-TROPSCH SYNTHESIS PRODUCTS SEPARATION AND SOLVENT RECOVERY SYSTEM
}

\author{
A Thesis \\ by \\ TALA KATBEH
Submitted to the Office of Graduate and Professional Studies of Texas A\&M University
in partial fulfillment of the requirements for the degree of \\ MASTER OF SCIENCE
}

Chair of Committee, Nimir Elbashir

Co-Chair of Committee, Mahmoud El-Halwagi

Committee Member, Ibrahim Hassan

Head of Department, M. Nazmul Karim

December 2017

Major Subject: Chemical Engineering

Copyright 2017 Tala Katbeh 


\begin{abstract}
Extensive research has been done in the advancement of gas-to-liquid (GTL) technology for producing a cleaner source of energy through the conversion of natural gas into ultra-clean fuels and value-added chemicals. The Fischer-Tropsch (FT) synthesis, which is a catalytic process that converts synthesis gas (or syngas, which is a mixture of $\mathrm{CO}$ and $\mathrm{H}_{2}$ ) into longer chain hydrocarbons is considered to be the heart of the GTL process. Conventional FT processes are currently utilizing two most common types of reactors: the multi-tubular fixed bed reactor (in which the reaction takes place in a gas phase medium) and the slurry bubble column reactor (where the reaction takes place in a liquid phase medium). However, they possess heat transfer and mass transfer limitations, respectively.

In order to avoid the challenges, the application of a supercritical fluid (SCF) solvent in the Fischer-Tropsch synthesis was introduced. The SCF-FT process, in essence, combines the benefits of the two major reactor technologies used in conventional GTL processes due to the SCF's gas-like diffusivity, liquid-like solubility and heat transfer.
\end{abstract}

The SCF-FT synthesis involves co-feeding the SCF solvent along with the syngas into the reactor at a specific solvent to syngas ratio ( set as 3:1 in this work). Introducing the supercritical solvent (which was selected to be n-hexane in this work) requires adjustments in the SCF-FT products' separation sequence due to the significantly large amount of solvent available in the process. The major additional costs 
associated with the SCF-FT synthesis is in the product separation and solvent recovery. For SCF-FT to be adopted on a large-scale, the economics from operation under high pressure supercritical conditions must exceed the additional cost required for the separation of the solvent.

The aim of this work is to construct an optimum separation design to target the separation of synthetic crude oil (or syncrude) obtained from SCF-FT synthesis while recovering the supercritical solvent. Aspen Plus ${ }^{\circledR}$ was used as the process simulator to determine the energy consumption and quantify the sensitivity of the various parameters on the solvent recoverability, purity, product yield, and operation feasibility while comparing it to the typical FT process.

Three separation sequences were developed using existing GTL plants as references. The three scenarios were compared with regards to their energy requirements. The simulation results showed that despite the addition of a large amount of solvent, the separation of the products, water, and the recovery of the solvent was achieved. 


\section{DEDICATION}

To my loving parents - my role models - who have supported me, encouraged me and made so many sacrifices to make me the person I am today. Thank you. 


\section{ACKNOWLEDGEMENTS}

I cannot express enough thanks to my advisor, Prof. Nimir Elbashir, for his guidance and support throughout the course of this research. His motivation, passion and conveyance of excitement regarding teaching had a lasting effect and provided me with great learning opportunities. Deepest gratitude to my co-advisor, Prof. Mahmoud ElHalwagi, who has offered invaluable assistance and support, and to my committee member, Prof. Ibrahim Hassan.

I am grateful for Prof. Elbashir's research group for their commitment and advice to improve my work. I would also like to acknowledge Dr. Buping Bao and Dr. Mohamed Noureldin for answering my questions and helping pave the way to my research. I am also thankful for the faculty members and staff at Texas A\&M University at Qatar. Thanks also go to my friends and colleagues for making it a delightful experience.

Thanks to my parents who have continuously provided me with love and support. Thanks for teaching me that my job in life is to learn and be happy. To my mother, thank you for your unceasing advice and for always being there for me. And my father, thank you for your encouragement and for leading me to where I am today. Lastly, thanks to my siblings: Mary (and Joel and Alexandra), Raji, and Joelle for making life joyful. 


\section{CONTRIBUTORS AND FUNDING SOURCES}

This work was supervised by a thesis committee consisting of Prof. Nimir Elbashir (advisor) and Prof. Mahmoud El-Halwagi (co-advisor) of the Department of Chemical Engineering, and Prof. Ibrahim Hassan of the Department of Mechanical Engineering.

The data analyzed in section 5.2 were conducted in part by Dr. Buping Bao and were published in 2010. All other work conducted for the thesis was completed by the student independently.

This work was made possible by a NPRP award [NPRP 7-843-2-312] from the Qatar National Research Fund (a member of the Qatar Foundation). The statements made herein are solely the responsibility of the authors. 


\section{TABLE OF CONTENTS}

Page

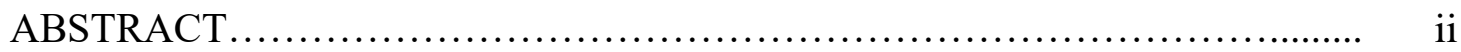

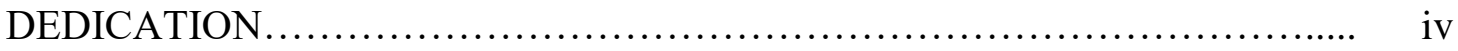

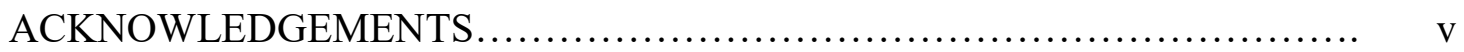

CONTRIBUTORS AND FUNDING SOURCES ........................... vi

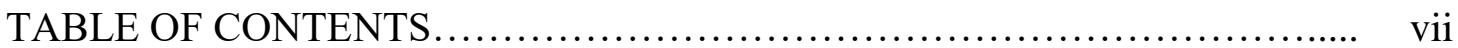

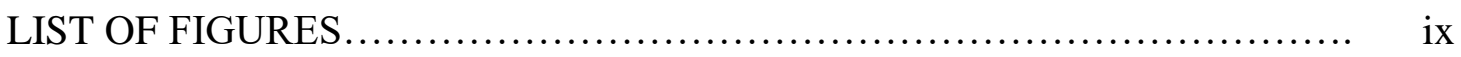

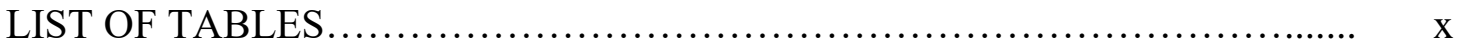

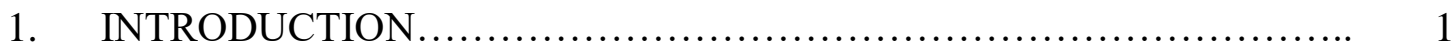

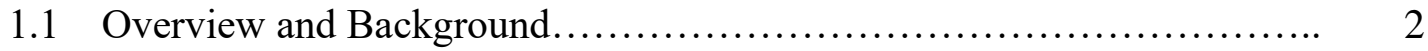

1.1.1. Syngas Generation (Natural Gas Reformer).................... 4

1.1.2. Fischer-Tropsch Synthesis................................... 6

1.1.3. Introduction on the Utilization of Supercritical Fluids in the FT

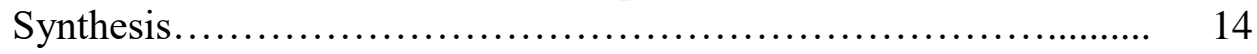

1.1.4. Products Upgrading........................................ 16

2. RESEARCH PROBLEM STATEMENT ............................. 23

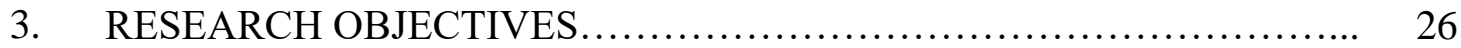

4. METHODOLOGY AND APPROACH............................... 27

5. RESULTS AND DISCUSSION .................................. 32

5.1 The FT reactor conditions....................................... 32

5.2 Scenario 1: Separation of the Heavy Components First................. 34

5.3 Alternate Separation Design.................................... 40

5.3.1. Scenario 2: Separation of the Water First...................... 43

5.3.2. Scenario 3: Separation of the Vapor and Liquid Components and Use of 3-phase Separator to Recover Water, Solvent, and Syngas... 50 


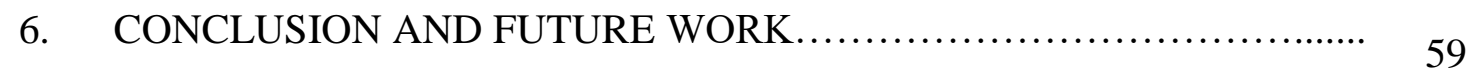

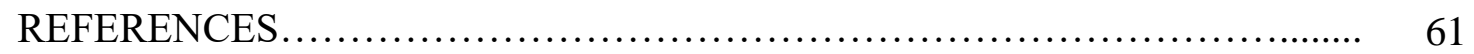

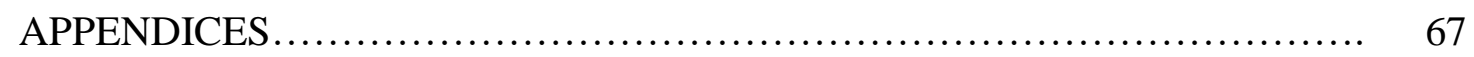




\section{LIST OF FIGURES}

Figure 1: World energy consumption by energy source, 1990-2040 (quadrillion Btu) (EIA, 2016).

Figure 2: Schematic of the overall GTL process ................................................... 3

Figure 3: LTFT and HTFT syncrude carbon number distribution with varying $\alpha$ values (de Klerk, 2007).

Figure 4: Types of reactors (circulating fluidized bed, fixed fluidized bed, slurry bubble, and multitubular fixed bed reactors)

Figure 5: Concept of a separation process ........................................................... 17

Figure 6: Flowsheet for supercritical solvent separation process ..............................19

Figure 7: SCF-FT synthesis product cuts ..........................................................24

Figure 8: The Process Design Approach ............................................................ 28

Figure 9: Scenario 1: Separation of the Heavy Components First ................................35

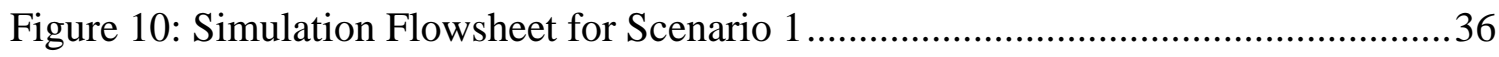

Figure 11: An example of a conventional GTL plant setup ......................................41

Figure 12: Another example of a conventional GTL plant setup ...............................42

Figure 13: Scenario 2 Simulation Flowsheet ........................................................ 43

Figure 14: Effect of Temperature and Pressure on Water Recovery ............................45

Figure 15: Effect of Temperature and Pressure on Solvent Recovery ..........................45

Figure 16: Effect of Temperature and Pressure on Syngas Recovery..........................46

Figure 17: Scenario 3 Initial Simulation Flowsheet .................................................51

Figure 18: Scenario 3 Modified Simulation Flowsheet ............................................52 


\section{LIST OF TABLES}

Page

Table 1: The common syngas generation technologies ..........................................

Table 2: The expansion of the FT industry ….......................................................

Table 3: Critical properties of pure solvents and of a 3:1 molar ratio of solvent: syngas mixture $\left(\mathrm{T}_{\mathrm{c}}\right.$ : critical temperature, $\mathrm{P}_{\mathrm{c}}$ : critical pressure, and $\rho_{\mathrm{c}}$ : critical density)

Table 4: Components of each type of fuel ................................................................ 18

Table 5: Samples of Simulation Studies of the GTL Process including the Supercritical FT Synthesis

Table 6: SCF-FT reactor outlet stream composition from the Aspen Plus simulation results

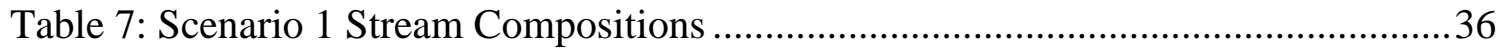

Table 8: Recovery of Scenario 1 Components in Exit Streams ..........................................

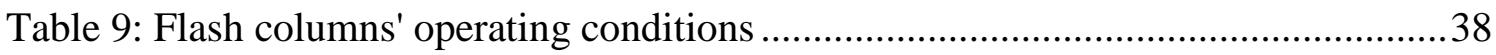

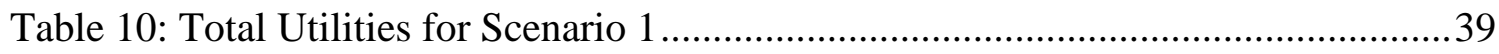

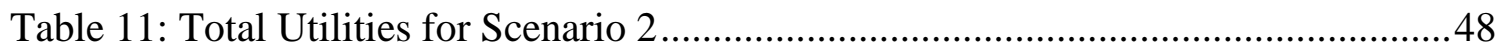

Table 12: Scenario 2 Stream Compositions ............................................................49

Table 13: Recovery of Scenario 2 Components in the Exit Streams ............................49

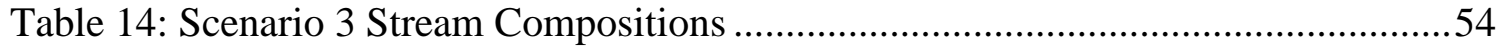

Table 15: Recovery of Scenario 3 Components in Exit Streams ................................55

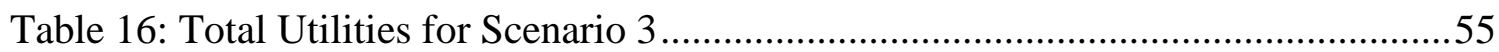

Table 17: Recovery of the Components for each Design............................................56

Table 18: Comparison of the Energy Consumed for each Scenario .............................56

Table 19: Comparing Scenario 3 energy consumption with and without solvent............57 


\section{INTRODUCTION}

Natural gas consumption is estimated to increase by $1.9 \%$ per year while coal is regarded as the slowest-growing energy source with a decline from $2.2 \%$ per year (over the past 30 years) to $0.6 \%$ per year in worldwide coal consumption from 2012 to 2040. This can be illustrated by the data represented in Figure 1 below (EIA, 2016). Due to the increase in consumption of natural gas, it is expected to result in an increase in demand for clean fuels and chemicals obtained from syngas (Elbashir, 2004; EIA, 2016).

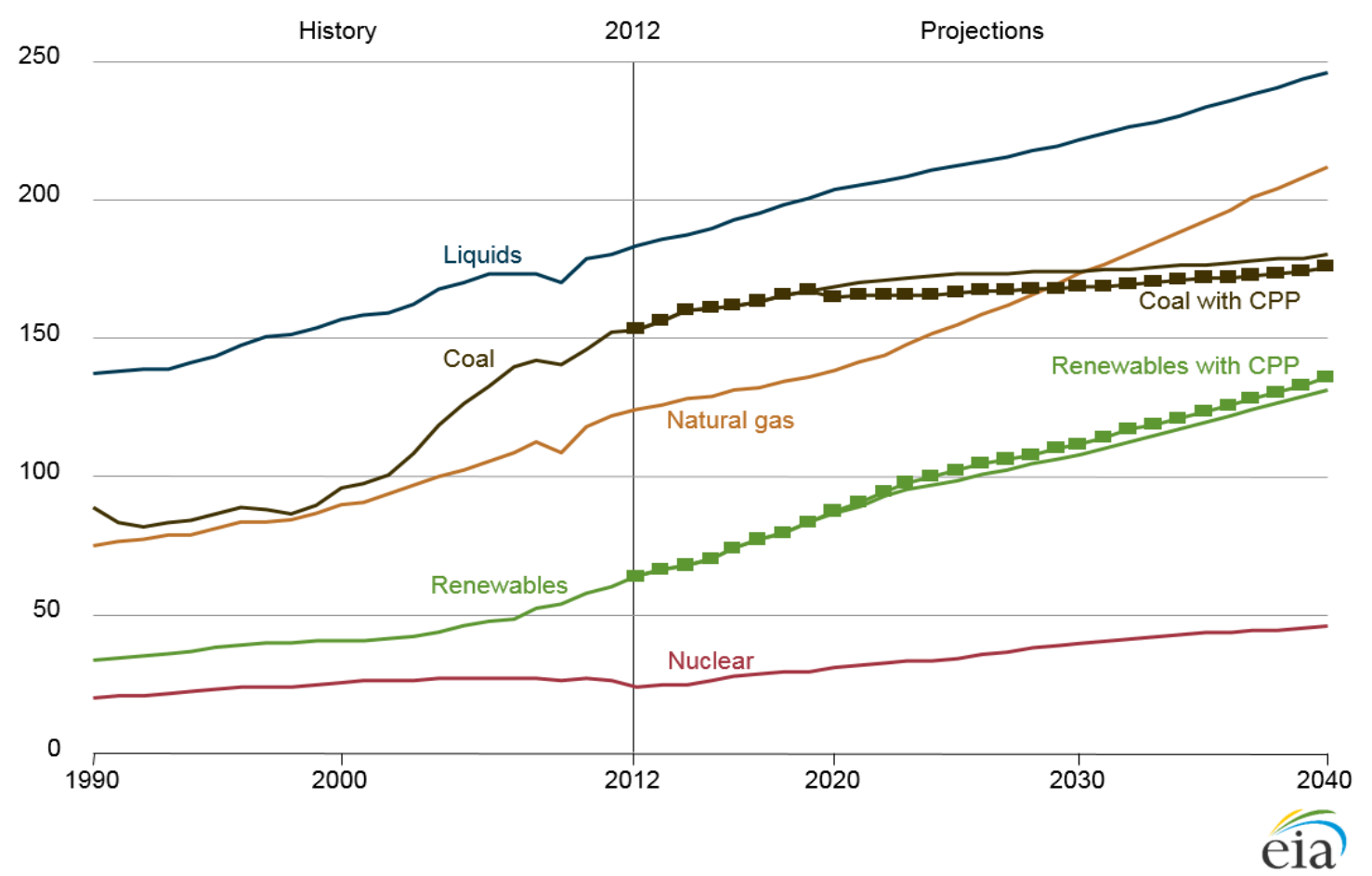

Figure 1: Reprinted from EIA, 2016: World energy consumption by energy source, 1990-2040 (quadrillion Btu) 
It is for that reason that the Fischer-Tropsch (FT) technology has drawn the attention of many researchers to develop novel and improved methods of obtaining the desired ultra-clean fuels and value-added chemicals from natural gas.

\subsection{Overview and Background}

For several decades, pivotal research in FT technology has attracted attention as a result of its provision of a significant new source of clean fuels as well as value-added chemicals from abundant natural resources. The heart of the gas-to-liquid (GTL) technology is the FT synthesis. The FT process involves an exothermic heterogeneous reaction over a cobalt-based or iron-based catalyst in which syngas (a mixture of carbon monoxide and hydrogen) is converted into hydrocarbons with a range of variable chain length (Dry, 2002; Steynberg, 2004). The hydrocarbons produced are referred to as synthetic crude oil - or syncrude.

The development of GTL technology using natural gas as feedstock through the FT synthesis evolved from coal-to-liquid (CTL) technology developed by Franz Fischer and Hans Tropsch to provide transportation fuels for German military machines during Worl War II. The GTL, then become attractive as a source of ultra-clean fuels that meet the stringent environmental regulations of the developed nations (Fischer and Tropsch, 1926; Dancuart and Steynberg, 2007; Stranges, 2007). 


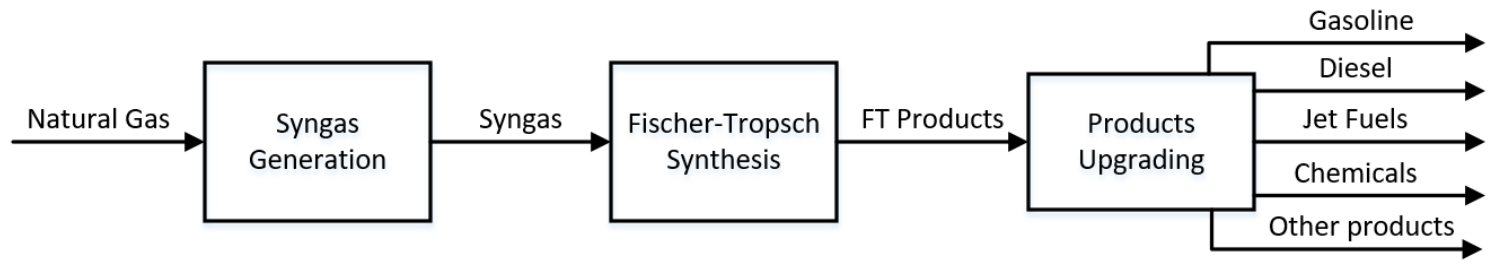

Figure 2: Schematic of the overall GTL process

The GTL technology consists mainly of three three processes as shown in Figure 2: the first block represents a reformer unit that converts natural gas into syngas; the second one denotes the FT reactor that converts the syngas into syncrude (long chain hydrocarbons, mostly paraffinic $\mathrm{C}_{\mathrm{n}} \mathrm{H}_{2 \mathrm{n}+2}$ ); and the last process represents a refinery section for the separation and upgrading of the hydrocarbon products to fuels and chemicals. 


\subsubsection{Syngas Generation (Natural Gas Refomer)}

Table 1 lists the common syngas generation technologies implemented commercially (Wilhelm et al., 2001; Yan et al., 2014; Arora and Prasad, 2016).

Table 1: The common syngas generation technologies

\begin{tabular}{|c|c|}
\hline Technology & \begin{tabular}{|l} 
Description \\
\end{tabular} \\
\hline $\begin{array}{l}\text { Steam methane reforming } \\
(\mathrm{SMR})\end{array}$ & $\begin{array}{l}\text { An endothermic catalytic reaction in which methane } \\
\text { and steam react to form syngas. } \\
\mathrm{CH}_{4}+\mathrm{H}_{2} \mathrm{O} \leftrightarrow \mathrm{CO}+3 \mathrm{H}_{2}, \Delta \mathrm{H}=206.1 \mathrm{~kJ} / \mathrm{mol}\end{array}$ \\
\hline Partial oxidation (POX) & $\begin{array}{l}\text { An exothermic reaction involving the conversion of } \\
\text { methane and oxygen to form syngas. } \\
\mathrm{CH}_{4}+1 / 2 \mathrm{O}_{2} \leftrightarrow \mathrm{CO}+2 \mathrm{H}_{2}, \Delta \mathrm{H}=-35.2 \mathrm{~kJ} / \mathrm{mol}\end{array}$ \\
\hline Autothermal reforming (ATR) & $\begin{array}{l}\text { Combines the previous two technologies such that } \\
\text { oxygen and steam react in an endothermic reaction } \\
\text { with methane to produce syngas. } \\
\mathrm{CH}_{4}+1 / 2 \mathrm{O}_{2} \leftrightarrow \mathrm{CO}+2 \mathrm{H}_{2}, \Delta \mathrm{H}=-35.2 \mathrm{~kJ} / \mathrm{mol} \\
\mathrm{CH}_{4}+\mathrm{H}_{2} \mathrm{O} \leftrightarrow \mathrm{CO}+3 \mathrm{H}_{2}, \Delta \mathrm{H}=206.1 \mathrm{~kJ} / \mathrm{mol}\end{array}$ \\
\hline Heat exchange reforming & $\begin{array}{l}\text { Utilizes high reforming temperature that can be } \\
\text { obtained from the reformed gas through heat } \\
\text { recovery thereby leading to a more compact size } \\
\text { with reduced emissions. }\end{array}$ \\
\hline Two-step reforming & $\begin{array}{l}\text { Comprises of the following steps: } \\
\text { 1. SMR } \\
\text { 2. Secondary oxygen-blown reforming }\end{array}$ \\
\hline $\begin{array}{l}\text { Dry reforming of methane } \\
(\mathrm{DRM})\end{array}$ & $\begin{array}{l}\text { An endothermic reaction that converts methane and } \\
\text { carbon dioxide into syngas. } \\
\mathrm{CH}_{4}+\mathrm{CO}_{2} \leftrightarrow 2 \mathrm{CO}+2 \mathrm{H}_{2}, \Delta \mathrm{H}=247.3 \mathrm{~kJ} / \mathrm{mol}\end{array}$ \\
\hline
\end{tabular}


In addition to the technologies mentioned in Table 1, extensive research is dedicated to reducing carbon footprints from a GTL process by utilizing the DRM process. The process limitations associated with DRM (carbon formation, high endothermicity, and low syngas ratio) are some of the areas that attract numerous research avenues. One such process that synergistically combines the benefits of the three reforming processes is the combined reforming of methane (CRM) which is shown to provide significant carbon dioxide conversion at low energy requirements when integrated in a GTL plant (Gabriel et al., 2014; Noureldin, Elbashir and El-Halwagi, 2014; Noureldin et al., 2015; Challiwala et al., 2017).

The choice of reformer technology depends on many factors (such as the overall size, the syngas ratio, and the temperature requirements); therefore, the selection process relies on a balance between the different reformer technologies with a significant consideration on the costs (Noureldin, Elbashir and El-Halwagi, 2014). The syngas production step requires a large investment as it is the cost determining stage of the GTL technology. If the syngas ratio produced does not meet the required ratio for the FT process, then the FT process might result in a considerably different product distribution. This would impact the plant economics and would lead to product losses and also influence the performance of downstream processes (Wilhelm et al., 2001). 


\subsubsection{Fischer-Tropsch Synthesis}

By the 1920s, the industrialized nations (such as Germany, Britain, France, Japan, Italy, and other countries) required petroleum as a crucial essentiality to their economies. At the onset of the twentieth century; however, Germany had faced a discernible lack of petroleum supply that had not been an issue prior to the start of the century due to their sufficient coal reserves. This change has occurred due to Germany's dependence on transportation fuels for its military machines. It is for that reason that innovators had done substantial research on producing synthetic liquid fuels. Germany became the first country to synthesize fuels from coal resources (Speight, 2007).

From 1910 to 1925 , Friedrich Bergius in Rheinau-Mannheim, Germany created the high-pressure coal hydrogenation process which was the first invention into synthesizing fuel from Germany's ample coal supply. Following that, in 1926, Franz Fischer (1877-1947) and Hans Tropsch (1889-1935) at the Kaiser Wilhelm Institute for Coal Research (KWI) in Mülheim invented the process for converting coal into syngas which can then, in turn, be converted into other hydrocarbons. This process was initially performed at low pressures of $1-10$ atm and a temperature of $180-200{ }^{\circ} \mathrm{C}$ and in the decade of its launch, cobalt catalysts were developed that were beneficial for this Fischer-Tropsch process (Stranges, 2007).

By 1944, their invention was utilized by nine commercial-sized FT plants in Germany in which the synthetic fuel production reached 23 million barrels (Stranges, 2007). The expansion of the FT development can be summarized in the table below (Dancuart and Steynberg, 2007). 
Table 2: The expansion of the FT industry

\begin{tabular}{|c|c|c|}
\hline Period & Stage & Details \\
\hline 1902-1928 & $\begin{array}{l}\text { Establishment of the } \\
\text { FT Technology }\end{array}$ & $\begin{array}{l}\text { Discovery of syngas conversion and patent } \\
\text { filings were made. }\end{array}$ \\
\hline 1929-1949 & $\begin{array}{l}\text { The cobalt catalyst } \\
\text { period }\end{array}$ & $\begin{array}{l}\text { The cobalt catalyst was beneficial for the } \\
\text { development of the FT process using coal as } \\
\text { feedstock. }\end{array}$ \\
\hline $1950-1990$ & $\begin{array}{l}\text { The iron catalyst } \\
\text { period }\end{array}$ & $\begin{array}{l}\text { Sasol developed four FT processes (two LTFT } \\
\text { and two HTFT) in South Africa. }\end{array}$ \\
\hline 1990-2004 & $\begin{array}{l}\text { The FT GTL } \\
\text { commercial period }\end{array}$ & $\begin{array}{l}\text { Developments using both iron and cobalt } \\
\text { catalysts and formation of PetroSA (Mossel Bay, } \\
\text { South Africa) and Shell GTL (Bintulu, Malaysia) } \\
\text { commercial plants. }\end{array}$ \\
\hline $2004-$ & $\begin{array}{l}\text { Commercial } \\
\text { expansion }\end{array}$ & $\begin{array}{l}\text { Development of ORYX GTL (Sasol) and Pearl } \\
\text { GTL (Shell) in Qatar and other proposals. }\end{array}$ \\
\hline
\end{tabular}


The chemistry of the reaction that convers natural gas to syngas followed by the FT reaction can be simplified as follows (Khodakov, Chu and Fongarland, 2007; Speight, 2007).

$$
\begin{gathered}
\mathrm{CH}_{4}+1 / 2 \mathrm{O}_{2} \rightarrow 2 \mathrm{H}_{2}+\mathrm{CO} \\
2 n \mathrm{H}_{2}+n \mathrm{CO} \rightarrow \mathrm{C}_{n} \mathrm{H}_{2 n}+n \mathrm{H}_{2} \mathrm{O} \\
(2 n+1) \mathrm{H}_{2}+n \mathrm{CO} \rightarrow \mathrm{C}_{n} \mathrm{H}_{2 n+2}+n \mathrm{H}_{2} \mathrm{O}
\end{gathered}
$$

The first reaction ( 1 ) shows the generation of syngas and the second and third reactions ( 3 ) represent the conversion of syngas into hydrocarbons, the Fischer-Tropsch synthesis. Conducting the FT reaction over a cobalt-based catalyst produces water as the main byproduct. However, conducting the FT reaction over an iron-based catalyst produces mainly $\mathrm{CO}_{2}$ as a byproduct due to its high activity for the WGS reaction (Choi et al., 1997). The presence of water activates the water-gas shift (WGS) reaction as described in equation 4. Therefore, over cobalt, the WGS reaction is negligible while over iron catalysts, it has a high activity (van der Laan, 1999).

$$
\mathrm{CO}+\mathrm{H}_{2} \mathrm{O} \rightleftarrows \mathrm{CO}_{2}+\mathrm{H}_{2}
$$

The cobalt-based catalyst is typically the preferred catalyst selected due to its longevity and high activity for the FT reaction (Vosloo, 2001).

The FT product distribution model generally follows the Anderson-Schulz-Flory (ASF) distribution model (Sie and Krishna, 1999). The hydrocarbon chain growth is represented by the chain growth probability factor ( $\alpha$-value) which is the fraction of the rate of propagation, $r_{P, n}$, to the sum of the rates of propagation and termination of the 
hydrocarbon chains, $r_{T, n}$, as described in equation 4 below. The chain length is represented by the carbon number $n$ (Förtsch, Pabst and Groß-Hardt, 2015).

$$
\alpha_{n}=\frac{r_{P, n}}{r_{P, n}+r_{T, n}}
$$

The mass fraction of the hydrocarbon products is represented by $W_{n}$ and is determined by the ASF equation (equation 6) below:

$$
W_{n}=n \alpha^{n-1}(1-\alpha)^{2}
$$

This model portrays that as the $\alpha$-value increases, the heavy hydrocarbons production increases. It is necessary to have information on the FT products' composition in order to determine the product fractions from the process.

The FT process is classified primarily into two operating modes: lowtemperature Fischer-Tropsch (LTFT) process, which ranges at temperatures between 200-240 ${ }^{\circ} \mathrm{C}$ and mainly use cobalt-based catalysts, and high-temperature FischerTropsch (HTFT) process that operates at temperatures between $300-350{ }^{\circ} \mathrm{C}$ and mainly use iron-based catalysts. They are selected depending on the desired final products as they differ in carbon number distribution (Figure 3). The HTFT process produces gasoline and alpha olefins while the LTFT process is used for the production of diesel and wax (de Klerk, 2007). 


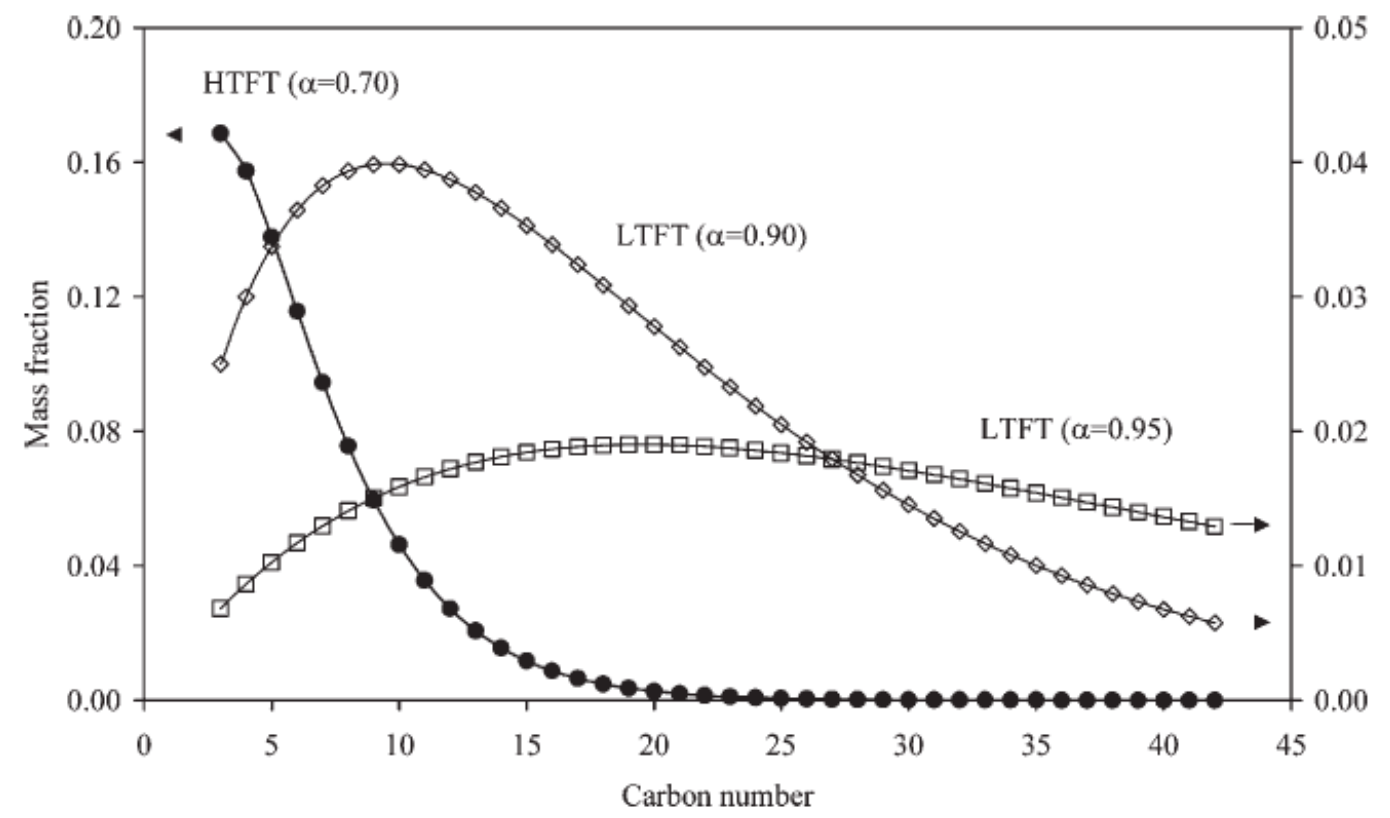

Figure 3: LTFT and HTFT syncrude carbon number distribution with varying $\alpha$ values (de Klerk, 2007)

\subsubsection{Conventional FT Reactors}

The following shows a summary of the history behind the reactor developments and implementations (Dry, 2002; Khodakov, Chu and Fongarland, 2007; de Klerk, 2011).

- In 1927 onwards, there was significant developments in fixed bed and circulating bed reactor which were critical for later industrial applications.

- After World War II, ARGE (Arbeitsgemeinschaft Ruhrchemie und Lurgi) worked on developing a large-scale process that utilizes a fixed bed FT reactor while Kellogg worked on circulating catalyst bed reactor technology. Both of those technologies were later used by Sasol. 
- The fixed fluidized bed reactor types were used as commercial reactors in the Brownsville, TX, plant in the mid-1950s. Those reactors, however, only operated for a short period of time.

- In the 1950s, the slurry bed reactors were studied by Kölbel

- In 1955, the Sasol One plant built in Sasolburg utilized Kellogg's technology of circulating fluidized beds. Improvements and accomplishments on the design of catalyst and reactors for those circulating fluidized bed reactors were known as Synthol reactors. The Sasolburg plant integrated both the LTFT ARGE and the HTFT Kellogg technologies in the process and 5 multitubular ARGE reactors were installed and are still in operation.

- Sasol Two and Sasol Three began production in Secunda in 1980 and 1982, respectively, using this circulating fluidized bed reactors type.

- In the late 1970 s, Sasol was simultaneously studying fixed fluidized bed reactors and one was implemented in the Sasolburg plant in 1984 and another in 1989 meeting all production expectations.

- The Sasol Mossgas plant began production in 1992 with similar larger type of circulating fluidized bed reactors.

- The Shell Bintulu plant in Malaysia began production in 1993 and had 4 multitubular reactors.

- In 1993, the Sasolburg plant added a slurry bed reactor which is still in operation and was found to have an equal production as that of the initial 5 ARGE reactors. 
- Between 1995 and 1999, the 16 circulating fluidized bed reactors in Secunda were replaced by 8 fixed fluidized bed reactors. Those reactors were the Sasol Advanced Synthol reactors. It is worth noting that approximately 35 years after the Brownsville, TX plant was shut down, Sasol used the same but improved - type of fixed fluidized bed reactors.

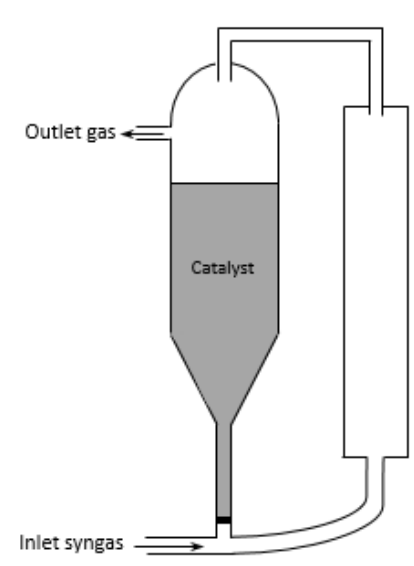

(A) Circulating fluidized bed reactor

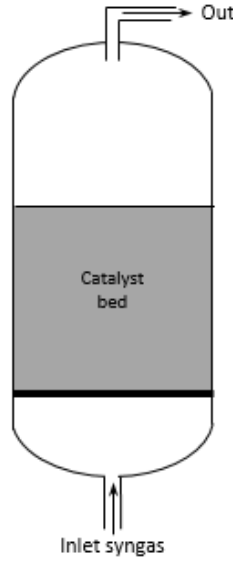

(B) Fixed fluidized bed reactor

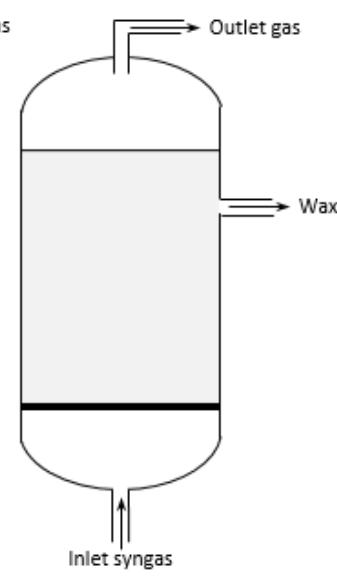

(C) Slurry bubble reactor

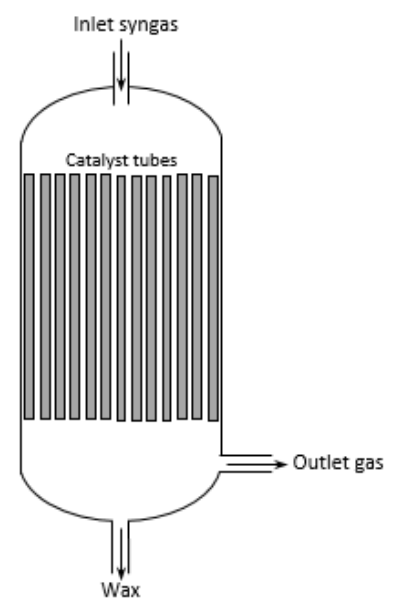

(D) Multitubular fixed bed reactor

Figure 4: Types of reactors (circulating fluidized bed, fixed fluidized bed, slurry bubble, and multitubular fixed bed reactors)

There are four types of conventional FT reactors currently used (Figure 4):

1) Circulating fluidized bed reactor

2) Fixed fluidized bed reactor

3) Slurry bubble reactor

4) Multitubular fixed bed reactor

As shown in Figure 4, the fluidized bed reactors operate as HTFT reactors while the multitubular and slurry phase reactors operate for LTFT processes. The primary 
distinction between the two operating conditions is that there is no liquid phase surrounding the catalyst particles in the HTFT reactor as that would lead to complications in its fluidization behavior (Steynberg et al., 2004).

To determine the products selectivity, the factors that affect the reaction would be the catalyst selection and the operating conditions. Therefore, for maximizing products with cuts heavier than gasoline or naphtha, the fluidized bed reactors are not effective options, and the fixed bed or slurry reactors are the suitable selections (Steynberg et al., 2004).

The LTFT multi-tubular reactor requires a large number of tubes to remove the heat released by the highly exothermic FT reaction. However, this results in high compression costs due to the high pressure drop. Additionally, since the multi-tubular reactor consists of a large number of tubes, this leads to a non-uniform temperature profile as well as an increase in the catalyst loading rate. This design leads to the problem of challenging economies of scale that requires a mega scale plant such as the Pearl GTL plant. To avoid the aforementioned issues, Sasol developed a slurry-bed FT reactor which uses a liquid phase media (heavy wax). The design results in a lower compression cost and a uniform temperature profile inside the reactor bed. Consequently, a high catalyst activity, as well as a high product selectivity, is maintained. The limitations faced in this type of reactor includes the separation of the solid catalyst from the liquid products in addition to the slow diffusion of the syngas in the liquid media (Yokota, Hanakata and Fujimoto, 1990; Elbashir et al., 2010; Bao, 2012). 
This work covers the development of a separation sequence for the products when utilizing FT synthesis in supercritical conditions. The results would show the feasibility of using such process and its competitiveness to the conventional method.

\subsubsection{Introduction on the Utilization of Supercritical Fluids in the FT Synthesis}

To avert the limitations posed by the fixed-bed reactor and the slurry reactor while also combining the simplicity of the former and the improved heat transfer characteristics of the latter, operating FT with supercritical fluid (SCF) conditions was introduced (Yokota, Hanakata and Fujimoto, 1990; Elbashir et al., 2010 (and refernces therein)). Utilizing a SCF has the unique characteristics of gas-like diffusivity as well as liquid-like heat transfer and solubility (Elbashir, Bao and El-halwagi, 2009). The application of SCF-FT is aimed mainly at LTFT reactor which operates at temperatures between $220-250{ }^{\circ} \mathrm{C}$ (Elbashir et al., 2010).

SCF-FT comes with the following considerations that would affect the costs of the process.

- The sizing of the reactor also needs to be taken into account due to the large amount of solvent.

- There is a significantly large amount of solvent, and for that reason, large containers and equipment are needed for the process.

- Using the SCF as a medium helps clean the catalyst of coke formation and would prevent the buildup of wax from the catalyst surface. This type of 
media adds to the lifetime of the catalyst and therefore, is cost effective and economical (Elbashir et al., 2005).

- SCF-FT mainly produces diesel while other conventional processes produce heavy hydrocarbons. It is for that reason that it reduces the large load of the hydrocracker, which in turn also reduces the catalyst costs (Elbashir and Roberts, 2005).

Considering these points and studying the details shows that any additional costs would not only have to do with the added compression costs for operating at a higher pressure as other factors impact the overall costs.

On the other hand, the hydrocarbon products produced from the FT synthesis are viable options for the solvent selection for the SCF-FT because of the followings (Elmalik et al. (2011)):

- Pentane $\left(\mathrm{C}_{5}\right)$ and hexane $\left(\mathrm{C}_{6}\right)$ could be selected as solvents either alone or blended because their critical properties are within the required reaction conditions for the cobalt-based FT synthesis.

- Heptane $\left(\mathrm{C}_{7}\right)$ is a challenging cut to upgrade

- Octane $\left(\mathrm{C}_{8}\right)$ is more complicated to purify than $\mathrm{C}_{6}$

- Naphtha has the advantage of familiar existing separation techniques in the existing GTL plants; however, it would result in the loss of significant products such as gasoline and jet fuel

Diesel can be used alone or blended as fuel but has a very high critical temperature 
A solvent of $\mathrm{C}_{5}-\mathrm{C}_{7}$ offers a reasonable choice as SCF due to their critical properties tabulated in Table 3 below (Elmalik et al., 2011). The supercritical solvent chosen for this work was hexane $\left(\mathrm{C}_{6}\right)$.

Table 3: Critical properties of pure solvents and of a 3:1 molar ratio of solvent:syngas mixture $\left(T_{c}\right.$ : critical temperature, $P_{c}$ : critical pressure, and $\rho_{c}$ : critical density)

\begin{tabular}{|l|c|c|c|c|c|c|}
\hline & $\begin{array}{c}\text { Pure } \mathrm{T}_{\mathrm{c}} \\
\left({ }^{\circ} \mathrm{C}\right)\end{array}$ & $\begin{array}{c}\text { Mix } \mathrm{T}_{\mathrm{c}} \\
\left({ }^{\circ} \mathrm{C}\right)\end{array}$ & $\begin{array}{c}\text { Pure } \mathrm{P}_{\mathrm{c}} \\
(\mathrm{bar})\end{array}$ & $\begin{array}{c}\text { Mix } \mathrm{P}_{\mathrm{c}} \\
(\mathrm{bar})\end{array}$ & $\begin{array}{c}\text { Pure } \rho_{\mathrm{c}} \\
\left(\mathrm{kg} / \mathrm{m}^{3}\right)\end{array}$ & $\begin{array}{c}\text { Mix } \rho_{\mathrm{c}} \\
\left(\mathrm{kg} / \mathrm{m}^{3}\right)\end{array}$ \\
\hline$n$-pentane & 196.6 & 192.0 & 33.6 & 82.0 & 232.27 & 213.7 \\
\hline$n$-hexane & 234.5 & 230.7 & 30.2 & 73.9 & 233.49 & 212.3 \\
\hline$n$-heptane & 266.85 & 264.2 & 27.4 & 67.6 & 235.44 & 211.2 \\
\hline
\end{tabular}

\subsection{4. $\quad$ Products Upgrading}

The basic concept of separation involves a multi-component feed stream that can be separated in order to obtain the desired products of specific purity and compositions (refer to Figure 5). While the notion seems simple, many considerations and methods are utilized to come about designing a separation process. 


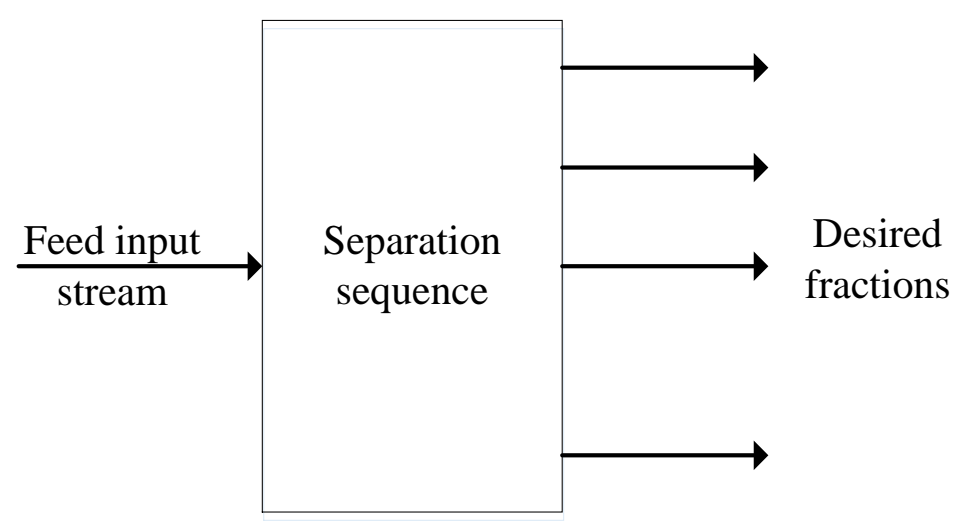

\section{Figure 5: Concept of a separation process}

The Fischer-Tropsch products possess the benefits of having zero sulfur content and very low aromaticity in the fuel fractions. The product fuel types vary from diesel, naphtha, gasoline, jet fuel, and LPG. The compositions of each type is shown in Table 4 . To obtain the desired product fuel types - which vary from LPG, naphtha, gasoline, jet fuel, and diesel - the FT products need to undergo an upgrading process.

The FT products need to undergo an upgrading process in order to obtain the desired saleable product cuts. Distillation is the first step to separate the syncrude into fractions in a refinery. Therefore, this work utilizes distillation based separation units to recover the products as well as the solvent. 
Table 4: Components of each type of fuel

\begin{tabular}{|l|l|}
\hline Fuel name & Components \\
\hline Fuel gas & $\mathrm{C}_{1}-\mathrm{C}_{2}$ \\
\hline LPG & $\mathrm{C}_{3}-\mathrm{C}_{4}$ \\
\hline Gasoline & $\mathrm{C}_{5}-\mathrm{C}_{12}$ \\
\hline Naphtha & $\mathrm{C}_{8}-\mathrm{C}_{12}$ \\
\hline Kerosene (jet fuel) & $\mathrm{C}_{11}-\mathrm{C}_{13}$ \\
\hline Diesel (fuel oil) & $\mathrm{C}_{13}-\mathrm{C}_{17}$ \\
\hline Middle distillates (light gas oil) & $\mathrm{C}_{10}-\mathrm{C}_{20}$ \\
\hline Wax & $\mathrm{C}_{19+}$ \\
\hline
\end{tabular}

Bao et al. (2012) focused on improving the SCF-FT separation sequence by removing the heavy components (heavy hydrocarbons $\mathrm{C} 20+$ ) first followed by the supplemental separation of the products into light components, water, and the solvent as fraction cuts in a supercritical Fischer-Tropsch process. Also, Bao, et al. (2012) reported an energy optimization technique for each of the sections presented in Figure 6 to determine the configuration of the products separation units. 


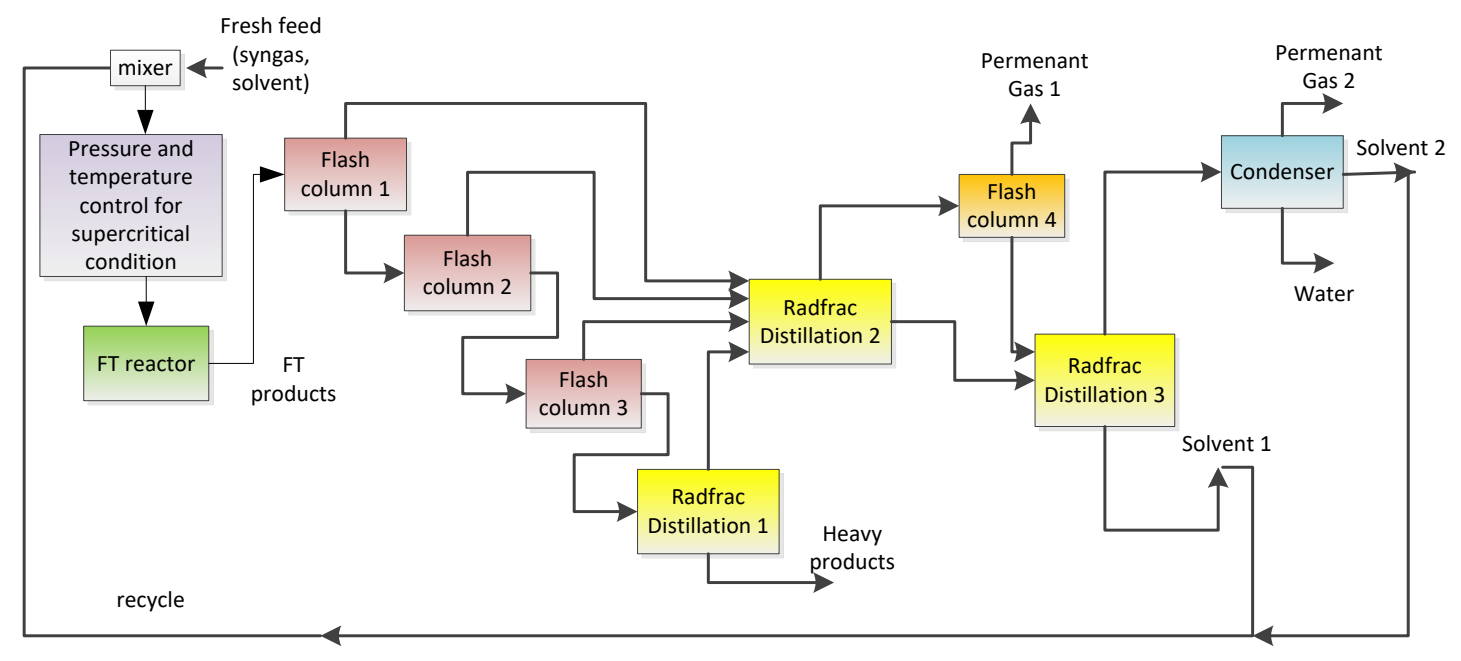

\section{Figure 6: Flowsheet for supercritical solvent separation process}

Four different optimization scenarios were studied including the following: (1)

optimizing the design of the flash column sequence, (2) optimizing the heavy

components recovery, (3) effects of replacing the Radfrac column with a flash column in

separating the solvent, and (4) effects of adding a condenser to increase the permanent

gas purity (refer to Figure 6). After simulating the different scenarios, an economic

analysis was performed. It showed which design had the highest return of investment,

the highest recoverability and purity, the highest sale of production, and the highest

energy saved. The information obtained from the economic analysis was very useful as it

would allow the designer to choose the best case depending on the objective of the

design.

Previous studies focused mainly on syngas generation and FT reaction (including some of the work listed in Table 5 below), with very few studies covered development of techniques for FT products separation. 
Table 5: Samples of Simulation Studies of the GTL Process including the Supercritical FT Synthesis

\begin{tabular}{|c|c|c|c|}
\hline Authors & Year & Title & Contributions \\
\hline Hao et al. & 2007 & $\begin{array}{l}\text { Simulation Analysis of a } \\
\text { Gas-to-Liquid Process } \\
\text { Using Aspen Plus }{ }^{\circledR}\end{array}$ & $\begin{array}{l}\text { Main focus was on simulating } \\
\text { the syngas generation and } \\
\text { Fischer-Tropsch synthesis } \\
\text { sections of a GTL process } \\
\text { using a cobalt-based and an } \\
\text { iron-based catalyst to establish } \\
\text { an optimal flowsheet structure. }\end{array}$ \\
\hline Abbaslou et al. & 2009 & $\begin{array}{l}\text { Review on Fischer- } \\
\text { Tropsch synthesis in } \\
\text { supercritical media }\end{array}$ & $\begin{array}{l}\text { Reviews previous work } \\
\text { involving supercritical FT } \\
\text { synthesis in which } \\
\text { comparisons in reaction } \\
\text { conditions and products } \\
\text { selectivity were made to the } \\
\text { conventional FT synthesis }\end{array}$ \\
\hline Elbashir et al. & 2009 & $\begin{array}{l}\text { An Approach to the } \\
\text { Design of Advanced } \\
\text { Fischer-Tropsch Reactor } \\
\text { for Operation in Near- } \\
\text { Critical and Supercritical } \\
\text { Phase Media }\end{array}$ & $\begin{array}{l}\text { The aim was to optimize the } \\
\text { FT synthesis reactor design } \\
\text { when utilizing a supercritical } \\
\text { solvent as a reaction media }\end{array}$ \\
\hline Kim et al. & 2009 & $\begin{array}{l}\text { A simulation study on } \\
\text { gas-to-liquid (natural gas } \\
\text { to Fischer-Tropsch } \\
\text { synthetic fuel) process } \\
\text { optimization }\end{array}$ & $\begin{array}{l}\text { Objective was to establish the } \\
\text { optimal reaction conditions } \\
\text { (for the ATR and FT synthesis) } \\
\text { to obtain maximum fuel } \\
\text { production }\end{array}$ \\
\hline
\end{tabular}


Table 5 Continued

\begin{tabular}{|c|c|c|c|}
\hline Authors & Year & Title & Contributions \\
\hline Elbashir et al. & 2010 & $\begin{array}{l}\text { Advancement of Fischer- } \\
\text { Tropsch Synthesis via } \\
\text { Utilization of } \\
\text { Supercritical Fluid } \\
\text { Reaction Media }\end{array}$ & $\begin{array}{l}\text { Reviews relevant research to } \\
\text { supercritical FT synthesis } \\
\text { including solvent selection, } \\
\text { catalyst selection, and reaction } \\
\text { design. The work also } \\
\text { describes the challenges of } \\
\text { commercializing supercritical } \\
\text { FT synthesis }\end{array}$ \\
\hline Bao et al. & 2010 & $\begin{array}{l}\text { Simulation, integration, } \\
\text { and economic analysis of } \\
\text { gas-to-liquid processes }\end{array}$ & $\begin{array}{l}\text { Determined an energy efficient } \\
\text { and economical GTL process } \\
\text { design through performing a } \\
\text { techno-economic analysis on } \\
\text { the optimized process }\end{array}$ \\
\hline Panahi et al. & 2011 & $\begin{array}{l}\text { A Natural Gas to Liquids } \\
\text { (GTL) Process Model for } \\
\text { Optimal Operation }\end{array}$ & $\begin{array}{l}\text { The primary goal was to } \\
\text { optimize the GTL process with } \\
\text { the focus on the auto-thermal } \\
\text { reformer and the cobalt-based } \\
\text { FT synthesis reaction }\end{array}$ \\
\hline Gabriel et al. & 2014 & $\begin{array}{l}\text { Targeting of the water- } \\
\text { energy nexus in gas-to- } \\
\text { liquid processes: A } \\
\text { comparison of syngas } \\
\text { technologies }\end{array}$ & $\begin{array}{l}\text { The aim was to design and } \\
\text { simulate conventional GTL } \\
\text { processes and reduce } \\
\text { emissions, power, and water } \\
\text { generation through heat and } \\
\text { mass integration }\end{array}$ \\
\hline
\end{tabular}


As an extension to the relevant work previously performed for SCF-FT product separation, present efforts propose an alternate method for addressing the challenges associated with SCF-FT product separation. The main aspect of this work is to separate water at earlier stages, before the medium and heavy hydrocarbons $\left(\mathrm{C}_{8+}\right)$. The reason for doing so is due to tremendous increase in treatment capacity that poses a larger load until the end. 


\section{RESEARCH PROBLEM STATEMENT}

The GTL technology is attractive because it converts abundant natural resources, such as natural gas, coal and biomass, to cleaner and environmentally friendly fuel products with zero sulfur content and no aromatics. The two main commercial FT reactors are the fixed-bed and the slurry bubble column. Each design has its own operational advantages: the fixed-bed reactor facilitates high diffusivity of the reactant to the catalyst pores and has higher reaction rates that resulted in higher syngas consumption rates, on the other hand the slurry-bubble column reactor provides better temperature control for the highly exothermic FT reaction and higher productivity in large scale reactors. However, these FT reactor technologies have technical limitations and challenges such as mass transfer and heat transfer limitations. Employing the unique temperature and pressure properties of a supercritical fluid in the FT synthesis would

overcome the limitations in typical FT processes and combines the advantages of the two major reactor technologies: improved heat management, long life of the catalyst, and selectivity control of the product distribution. This is due to the gas-like transport properties and the liquid-like solubility and heat capacity that the SCF possesses.

However, utilizing SCF in FT reaction complicates the product separation process since the existence of large amount of solvents with the reaction mixture require optimized design for the solvent and products recovery process. The products of the SCF-FT can be aggregated into five fractions: the permanent gases $\left(\mathrm{H}_{2}, \mathrm{CO}\right.$, and $\left.\mathrm{CO}_{2}\right)$, the light hydrocarbons $\left(\mathrm{C}_{1}-\mathrm{C}_{4}\right)$, the solvent fraction $\left(\mathrm{C}_{5}-\mathrm{C}_{7}\right)$, the water fraction, and the 
medium distillate and heavy components $\left(\mathrm{C}_{8+}\right)$. However, the products are typically separated into three cuts: the permanent gases and light hydrocarbons, the solvent and water, and the heavy hydrocarbons (see Figure 7). The major additional cost in the SCFFT synthesis is the product separation and solvent recovery and the solvent being the middle cut with the water adds to the complications and challenges of separating the solvent.

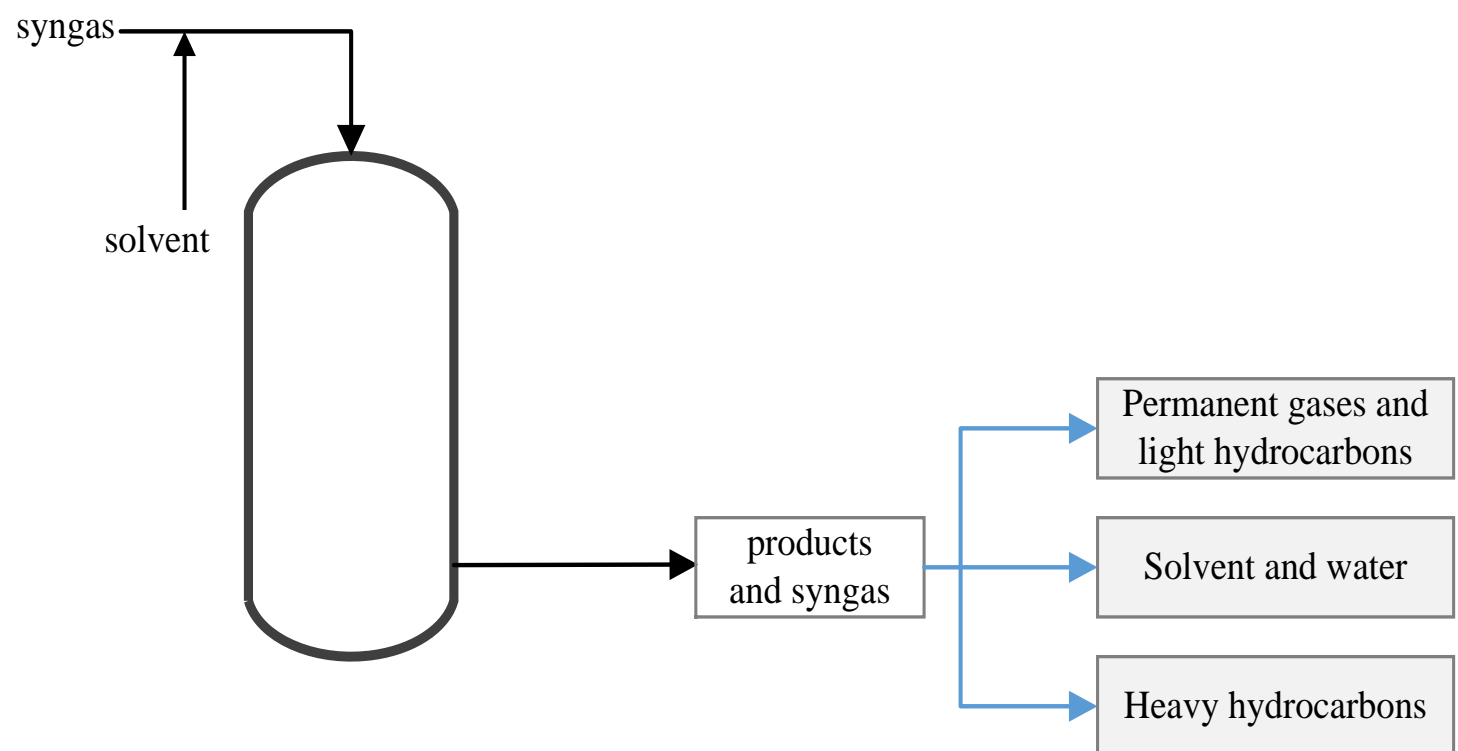

Figure 7: SCF-FT synthesis product cuts

As shown in Figure 7, the solvent is co-fed into the reactor alongside the syngas (in this work, the solvent to syngas molar ratio was 3:1 as it results in high CO conversions as well as good methane selectivity and chain growth probability ) and therefore, there is a significantly large amount of solvent in the process. The addition of the supercritical solvent as a feed to the FT reactor requires adjustments and further 
considerations to the products' separation sequence since it is at a large amount. Having this significant amount of solvent means that the equipment sizes would be larger and thus, the size of the entire process would be larger than that of a conventional one (compared to the gas phase FT technology). The solvent fraction is also a portion of the reaction products (e.g., light naphtha) and this adds to the amount of solvent available in the products stream that is to be separated. Therefore, the main challenge will be to establish an optimized separation sequence for the SCF-FT products and solvent recovery system. 


\section{RESEARCH OBJECTIVES}

The purpose of this work is to design a separation sequence for the syncrude obtained from SCF-FT synthesis while separating the typical FT products and recovering the supercritical solvent that would be recycled back to the reactor. The separation sequence needs to be operationally feasible and the products yield, solvent recovery, and energy consumption need to be considered when selecting the designs. The separation sequences are to be compared to existing conventional processes implemented commercially.

The goal was achieved through the following tasks:

1. An initial separation design was constructed

2. Various separation sequences were proposed and analyzed

3. The sequences were optimized to determine the one with the least energy requirements

It is expected that the operational costs of the SCF-FT can be competitive compared to the commercial GTL process. And any additional fixed costs for using a SCF-FT process could be due to the additional compression and separation costs from operating at a higher pressure with a large amount of the supercritical solvent. 


\section{METHODOLOGY AND APPROACH}

The study was conducted by utilizing Aspen Plus ${ }^{\circledR}$, a preeminent chemical process engineering software that allows the user to design, simulate, and optimize a process model. It enables the user to construct flowsheets, perform product analysis, and optimize the process and the equipment design through the prediction of the energy consumption and costs by using the economic analysis, sensitivity analysis and optimization tools that are built in the software (Aspen Technology, 2017).

Process design is typically accompanied by the methodical construction of multicomponent separation sequences to yield products of relatively pure components. The steps to accomplishing that involves determining separation methods and sequences and then selecting the best separation sequence to achieve the optimal target. Establishing separation flowsheets involves the use of heuristic rules to "narrow down" the potential sequences (Malek and Glavic, 1994).

Since the goal of this research is to determine an optimum separation design, the successive steps taken in order to achieve the desired outcome are illustrated in Figure 8 (remodeled from Cano-Ruiz \& McRae (1998) and Bao et al. (2010)). First, a base case flowsheet was generated using an existing GTL plant design as a framework while taking into account the common heuristic rules. Next, the flowsheet was simulated using Aspen Plus as a modeling tool to determine the suitable unit conditions and the stream compositions around each equipment. Each local section was then optimized by conducting a sensitivity analysis on the different equipment. The results enabled the 
selection of the optimum operating conditions and allowed the avoidance of unsuitable conditions. The sensitivity analysis resulted in the process conditions optimization. If the desired outcome was not met, the previous steps were repeated until a valid flowsheet was obtained. Once each equipment was optimized and the desired outcomes were achieved, it was possible to identify the feasibility of the process and determine its comparability to an existing plant.

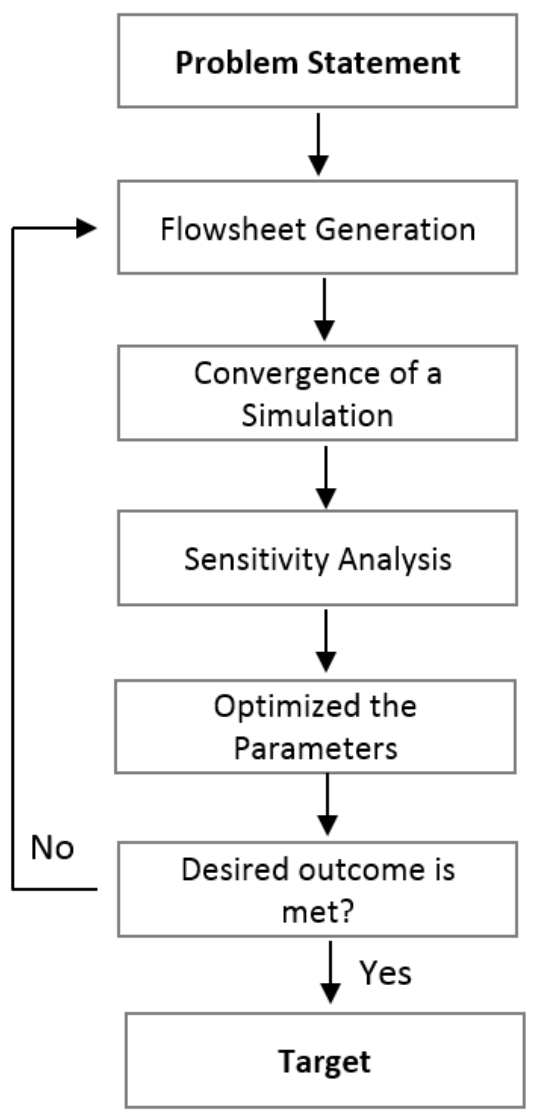

Figure 8: The Process Design Approach 
For the process simulation, the selected thermodynamic model was the NonRandom Two-Liquid Redlich-Kwong (NRTL-RK) property method. It was selected to take into account the polar nature of water. The simulation takes into account the material and energy balances of the process. The NRTL-RK method utilizes the NRTL liquid phase activity coefficient model and the Redlich-Kwong equation of state, which calculates the thermodynamic properties of the vapor phase. It also uses the Rackett model to compute the liquid molar volumes and Henry's law for supercritical components (Aspen Technology, 2013).

Through the utilization of engineering heuristics, the viable options to approach the separation of the SCF-FT products is through the following:

1) Remove the heavy first

2) Remove the most volatile first

3) Remove the water first

4) Remove the fraction with the highest weight percent

In the SCF-FT process, in order to start the separation with the removal of the fraction with the highest weight percent (which is the solvent fraction), this option would - in essence - simultaneously occur with options 2 and 3 in which the gases and the water fractions would be separated as well. To separate the $\mathrm{C}_{6}$ solvent, it would have to be separated with another fraction since it is a middle cut. Removing the solvent with the water would not be the best option since water is available at a significant amount (since the water is produced at a ratio of $1: 1$ with the $\mathrm{CO}$ reacted) and comprises $7 \%$ of the SCF-FT products and it needs to be separated as well. Therefore, the most suitable 
method would be to use a three-phase separator - as comparable to what is used in industry - in which the permanent gases, the solvent and hydrocarbon products, and the water would be separated.

The work covers alternative separation methods for the SCF-FT products. An initial separation sequence design was simulated in which the heavy components were initially separated with the gases, middle distillate, solvent, and water separated in the final stages.

An alternative approach is to tackle the products separation by using three-phase separation units in order to remove the majority of the water produced in order for it to not be carried on until the end. Separating the water in the early stages would eliminate the need for it to act as an inert component through the later separation stages and would reduce the need of having larger equipment sizes and larger flowrates along the process.

The separation sequences were optimized by performing a sensitivity analysis for each separation unit in the flowsheet. It is especially essential for optimizing the distillation columns in the process such that the energy consumption is reduced while maintaining maximum product separation. The optimization process mainly consists of the following:

1. The optimization function

2. The design variables

3. The constraints

In the case for optimizing the distillation column, the optimization function was to determine the reboiler and condenser duty and select the conditions at which the duties 
were minimal. The design variables were the molar reflux ratio, the feed stage, and the feed temperature. The constraints would be the recovery of the desired output products from the distillate and bottoms streams.

The sensitivity analysis performed on the three-phase separators and the flash columns, on the other hand, involved determining the effect of changing the feed stream's conditions on the separation such that maximum recovery and purity are reached. 


\section{RESULTS AND DISCUSSION}

\subsection{The FT reactor conditions}

The SCF-FT reactor conditions used were at a temperature of $240{ }^{\circ} \mathrm{C}$ and a pressure of 45 bar. The reaction takes place on a cobalt catalyst with the syngas feed molar ratio $\mathrm{H}_{2} / \mathrm{CO}$ of 2.15 and $75 \%$ of the $\mathrm{CO}$ is reacted (Dry, 2002; Bao, El-Halwagi and Elbashir, 2010). The solvent selected for this was hexane, $\mathrm{C}_{6}$ due to its supercritical properties as its critical temperature and pressure are $234.5^{\circ} \mathrm{C}$ and $30.2 \mathrm{bar}$, respectively. This solvent was fed to the reactor along with the syngas at a molar ratio of 3:1 (Elbashir et al., 2005). For the products distribution, the ASF products distribution model was used and the chain growth probability factor ( $\alpha$-value) was 0.96 . The SCF-FT products stream data (named FTPROD) can be found in Appendix A (Elbashir, Bao and ElHalwagi, 2009). The hydrocarbon products range from $C_{1}$ up to $C_{100}$; however, for ease of computation in the simulation, all hydrocarbons with Cetane Number larger than 30 were accumulated as $\mathrm{C}_{30+}$ components. The molar composition of the FTPROD stream consists of approximately $7.2 \%$ syngas, $7 \%$ water, $85.4 \%$ solvent, and $0.4 \%$ hydrocarbon products (with the molar flowrates represented in Table 6). It can be noted that the solvent constitutes the majority of the reactor outlet stream composition. 
Table 6: SCF-FT reactor outlet stream composition from the Aspen Plus simulation results

\begin{tabular}{|l|l|l|}
\hline Component & Mole Flow (kmol/hr) & Mole Fraction (\%) \\
\hline Syngas & 4,599 & 7.20 \\
\hline $\mathrm{H}_{2} \mathrm{O}$ & 4,536 & 7.09 \\
\hline $\mathrm{C}_{1}-\mathrm{C}_{5}$ & 33.5 & 0.05 \\
\hline $\mathrm{C}_{6}$ & 54,628 & 85.4 \\
\hline $\mathrm{C}_{7+}$ & 187 & 0.29 \\
\hline Total & 63,983 & 100 \\
\hline
\end{tabular}




\subsection{Scenario 1: Separation of the Heavy Components First}

The initial design for the SCF-FT synthesis product separation was selected as shown in Figure 9 below (using Bao et al. 2012 described in Figure 6 as the starting point). The flowsheet was simulated in Aspen Plus ${ }^{\circledR}$ (Figure 10) using the NRTL-RK property method, which was selected based on the FT products properties as it takes into account the polar nature of water available in the products. This property method enables the calculation of the thermodynamic properties of the vapor phase as well as utilizes Henry's law for the supercritical components (Aspen Technology, 2013). The FT reactor conditions used were at a temperature of $240{ }^{\circ} \mathrm{C}$ and a pressure of 45 bar (Fan and Fujimoto, 1999). The high pressure is beneficial to be utilized for the separation. The stream results' data obtained from the simulation can be found in Appendix C. 


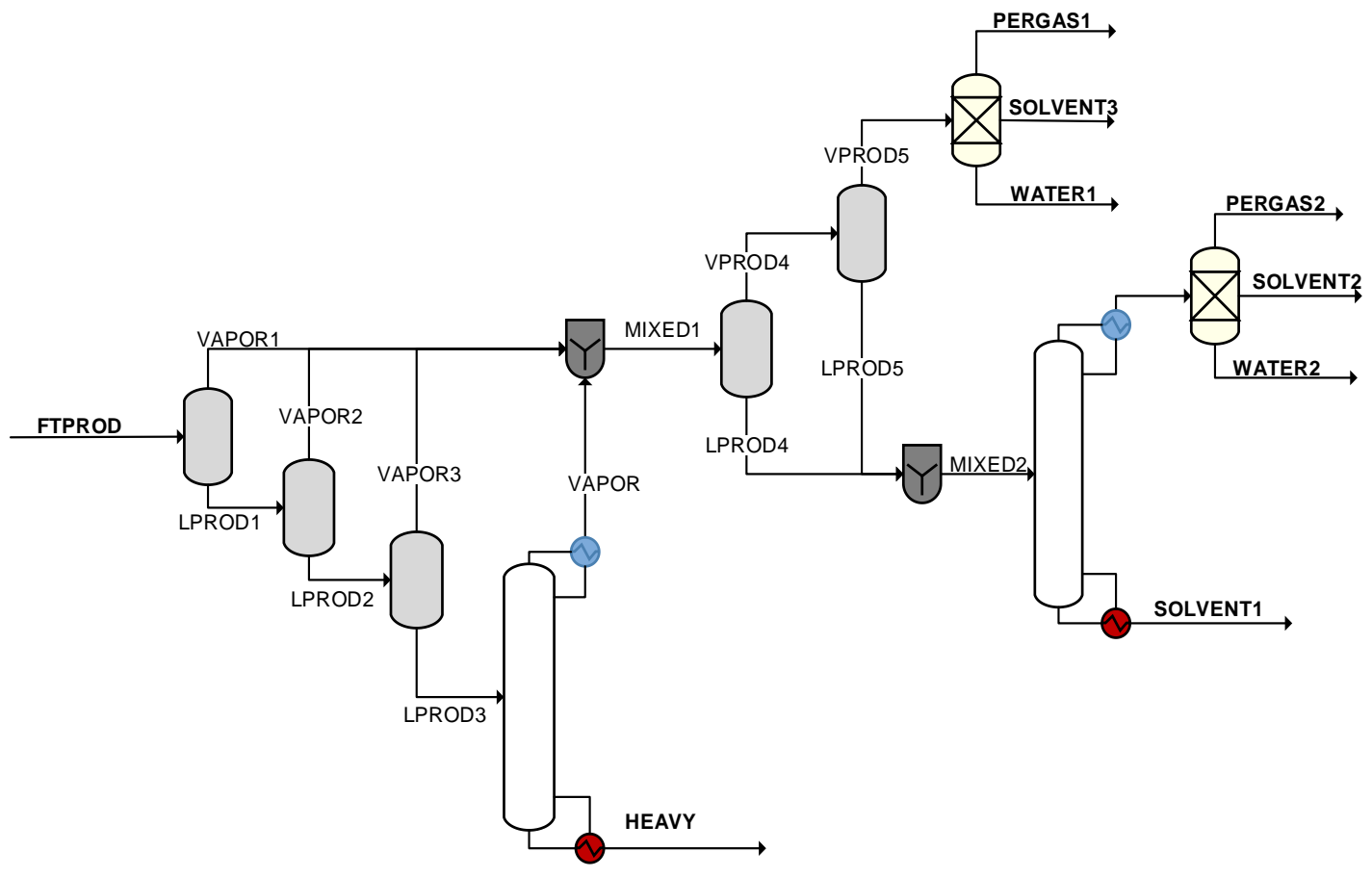

Figure 9: Scenario 1: Separation of the Heavy Components First 


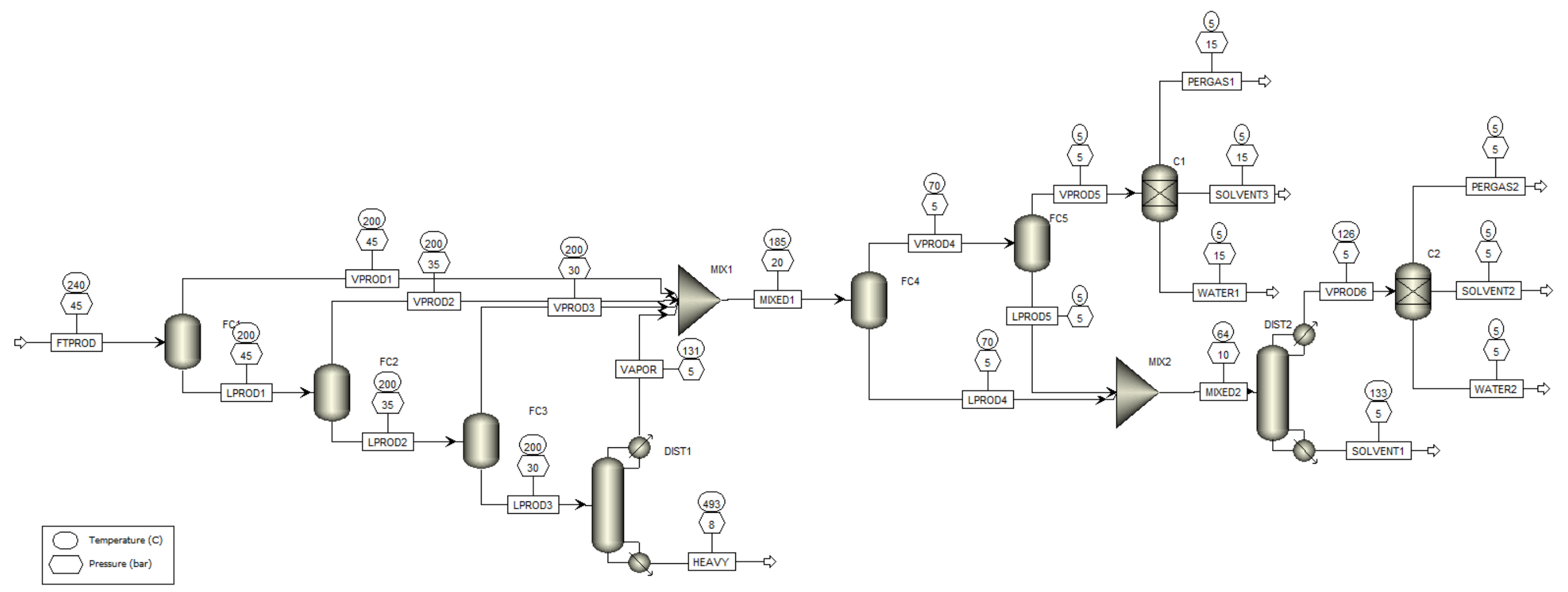

Figure 10: Simulation Flowsheet for Scenario 1

Table 7: Scenario 1 Stream Compositions

\begin{tabular}{|c|c|c|c|c|c|c|c|c|c|c|c|c|c|c|c|c|}
\hline $\begin{array}{l}\text { Mole } \\
\text { frac }(\%)\end{array}$ & FTPROD & VPROD1 & \begin{tabular}{|l|} 
LPROD1 \\
\end{tabular} & \begin{tabular}{|l|} 
VPROD2 \\
\end{tabular} & \begin{tabular}{|l|} 
LPROD2 \\
\end{tabular} & VPROD3 & LPROD3 & VAPOR & HEAVY & PERGAS1 & SOLVENT3 & WATER1 & \begin{tabular}{|l|} 
SOLVENT \\
\end{tabular} & \begin{tabular}{|l|} 
PERGAS2 \\
\end{tabular} & SOLVENT2 & WATER2 \\
\hline Syngas & 7.19 & 12.9 & 0.09 & 7.79 & 0.09 & 4.85 & 0.07 & 0.07 & 0 & 99.2 & 1.47 & 1.43 & 0 & 97.3 & 2.17 & 2.11 \\
\hline $\mathrm{H} 2 \mathrm{O}$ & 7.09 & 6.96 & 0.29 & 15.2 & 0.29 & 14.3 & 0.24 & 0.24 & 0 & 0.06 & 0.17 & 98.5 & 0 & 0.18 & 0.20 & 97.7 \\
\hline C1-C5 & 0.05 & 0.03 & 0.04 & 0.07 & 0.04 & 0.08 & 0.04 & 0.04 & 0 & 0.10 & 0.12 & 0.06 & 0 & 0.80 & 0.34 & 0.24 \\
\hline C6 & 85.4 & 41.4 & 99.0 & 76.9 & 99.0 & 80.7 & 99.0 & 99.6 & 1.41 & 0.60 & 98.2 & 0 & 99.9 & 1.70 & 97.3 & 0 \\
\hline $\mathrm{C} 7+$ & 0.29 & 0.02 & 0.62 & 0.03 & 0.62 & 0.03 & 0.62 & 0 & 98.6 & 0 & 0 & 0 & 0.02 & 0 & 0 & 0 \\
\hline
\end{tabular}


Table 8: Recovery of Scenario 1 Components in Exit Streams

\begin{tabular}{|l|l|l|l|l|l|l|l|l|}
\hline Recovery (\%) & HEAVY & PERGAS1 & SOLVENT3 & WATER1 & SOLVENT1 & PERGAS2 & SOLVENT2 & WATER2 \\
\hline Syngas & 0 & 94.8 & 0.03 & 0 & 0 & 0.81 & 2.24 & 2.12 \\
\hline $\mathrm{H}_{2} \mathrm{O}$ & 0 & 0.06 & 0 & 0.23 & 0 & 0 & 0.21 & 99.5 \\
\hline $\mathrm{C}_{1}-\mathrm{C}_{5}$ & 0 & 13.5 & 0.36 & 0.02 & 4.63 & 0.91 & 48.0 & 32.6 \\
\hline $\mathrm{C}_{6}$ & 0 & 0.05 & 0.19 & 0 & 91.3 & 0 & 8.46 & 0 \\
\hline $\mathrm{C}_{7+}$ & 93.5 & 0 & 0 & 0 & 6.50 & 0 & 0 & 0 \\
\hline
\end{tabular}

The separation starts with a flash column sequence, FC1, FC2, and FC3, which separates the middle distillate and the heavy components $\left(\mathrm{C}_{8+}\right)$ from the lighter components (this includes the permanent gases, the solvent, and the water). The flash columns are operated in this arrangement as it results in a successive drop in the columns' pressures. That is followed by a Radfrac distillation column (DIST1) that separates the heavier products $\left(\mathrm{C}_{8+}\right)$ from the vapors. The vapor streams are then mixed and inputted into a series of two-phase flash drums which further separate the lighter components: the permanent gases. The distillation column, DIST2, recovers most of the solvent while the condensers, $\mathrm{C} 1$ and $\mathrm{C} 2$, separate the permanent gases from the remaining water and solvent. The streams' compositions and the recovery of the components in the exit streams can be found in Table 7 and Table 8, respectively.

The flash columns operating conditions were as illustrated in Table 9. The temperature was kept constant while the pressures gradually decreased along the series of flash separators in order to maximize the separation. These conditions were selected based on a previous sensitivity analysis (Bao, 2012) which showed that at these specific 
temperatures and pressures the heavy components recovery met the target of this separation sequence.

Table 9: Flash columns' operating conditions

\begin{tabular}{|l|l|l|}
\hline Flash Column & Temperature $\left({ }^{\circ} \mathrm{C}\right)$ & Pressure (bar) \\
\hline FC1 & 200 & 45 \\
\hline FC2 & 200 & 35 \\
\hline FC3 & 200 & 30 \\
\hline
\end{tabular}

The distillation columns (DIST1 and DIST2) have 30 stages and are operating at a pressure of 5 bar. The bottoms rate was specified for each column in order to recover the desired components (the heavy components for DIST1 and the solvent for DIST2). It was found that as the bottoms rate increases, the recoverability of the heavier components increases. The feed stage was determined by studying the effect of the reboiler duty and the recoverability of the heavy components on the inlet stage. The flash columns, FC4 and FC5, were both at a pressure of 5 bar but at decreasing temperatures of $70^{\circ} \mathrm{C}$ and $5^{\circ} \mathrm{C}$, respectively. The low temperature of FC5 enabled the condensation of the liquids such that the majority of the permanent gases can be recovered. From the results obtained, $93.5 \%$ of the middle distillate and heavy components were recovered in the HEAVY stream, $95.6 \%$ of the syngas were recovered in the PERGAS streams, $99.95 \%$ of the solvent was recovered in the SOLVENT streams, and $99.7 \%$ of the water was recovered in the WATER streams. As for the energy consumption, the heating 
utilities amounted to 574.6 MW while the cooling utilities were 1227 MW where the total energy consumed was $1802 \mathrm{MW}$. The details are shown in Table 10 below.

Table 10: Total Utilities for Scenario 1

\begin{tabular}{|l|l|l|}
\hline & Heating Utilities (MW) & Cooling Utilities (MW) \\
\hline FC1 & - & -220.0 \\
\hline FC2 & 2.155 & - \\
\hline FC3 & 1.485 & - \\
\hline FC4 & - & -610.2 \\
\hline FC5 & - & -73.91 \\
\hline DIST1 Condenser & - & -146.5 \\
\hline DIST1 Reboiler & 201.7 & - \\
\hline DIST2 Condenser & - & -55.91 \\
\hline DIST2 Reboiler & 369.3 & - \\
\hline C1 & - & -1.055 \\
\hline C2 & - & -1227 \\
\hline Total & 574.6 & \\
\hline
\end{tabular}




\subsection{Alternate Separation Design}

An alternative approach to separating the products from the SCF-FT synthesis is to start by removing the water at the initial stages of separation. The main purpose is to avoid carrying the water on throughout the process as it would lead to an unnecessary larger treatment capacity as it acts as an inert component along the process.

A typical commercial GTL plant is illustrated in Figure 11 and it shows a simplified description to the Fischer Tropsch unit and the separation/refining units. The syngas enters the FT reactor that is a low-temperature slurry bed reactor for this case. Water is initially knocked out using three-phase separators and the light gases are further separated in which the tail gas is sent for further hydrocarbon recovery while the syngas is recycled as an external recycle stream back to the reformer in the syngas production unit. Meanwhile, the heavy ends recovered (HER) and the hydrocarbon condensate is further separated through the hydrocracker, followed by a series of hot and cold highpressure and low-pressure flash separation units. They are then taken to a stripper column and a fractionator to produce the final cuts: LPG product, light and heavy naphtha product, and diesel product. For this work, however, the focus would only be on the separation occurring prior to the hydrocracker as highlighted in the setup. It should be noted that the hydrocracking of the heavy hydrocarbons was not taken into account for the SCF-FT separation sequence simulations. 


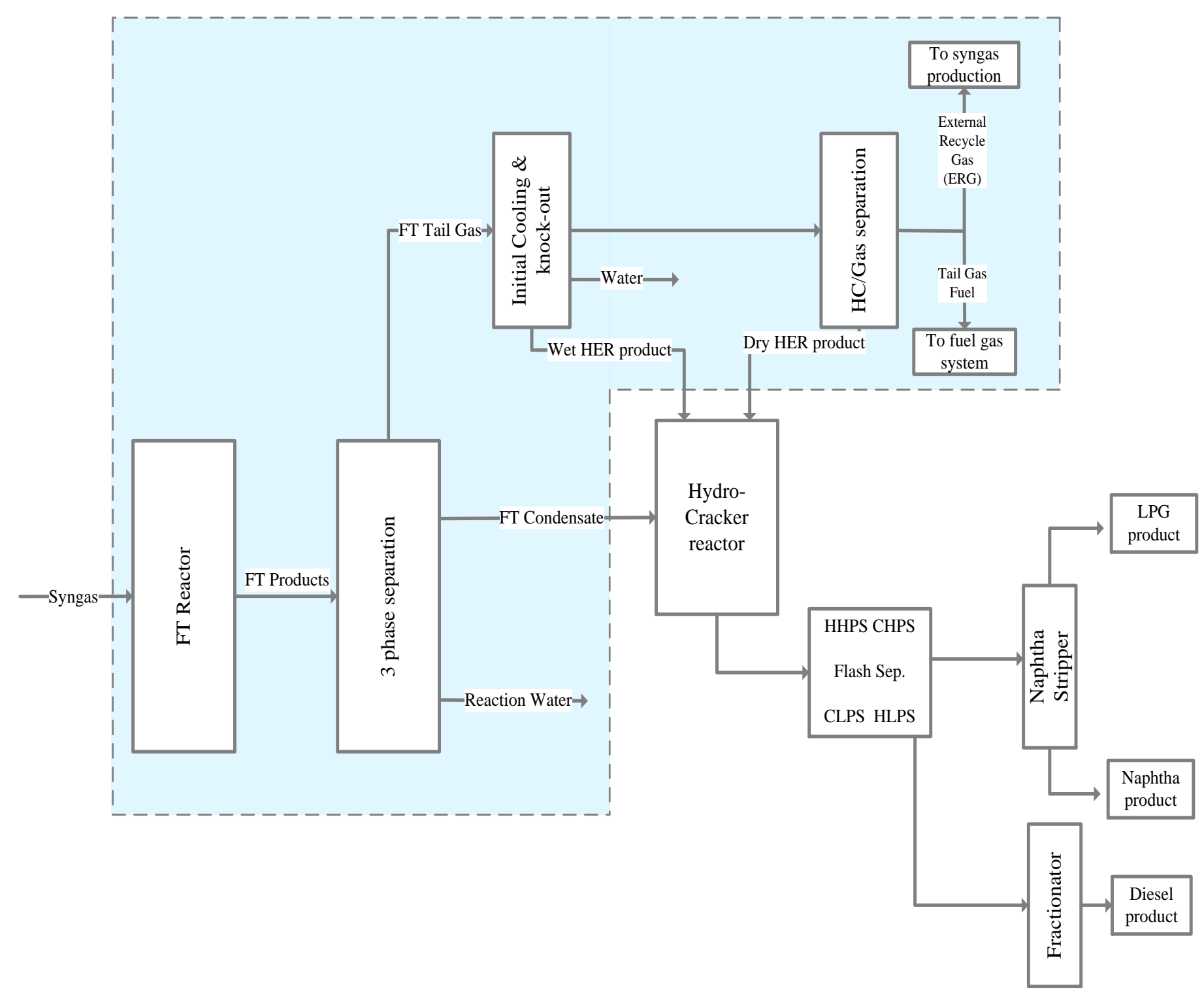

Figure 11: An example of a conventional GTL plant setup 
Another conventional setup can be shown in Figure 12 below. In this setup, it clearly shows the vapor and liquid components exiting in a separate stream out of the FT reactor. Whereas, the gaseous components first undergo a three-phase separation for water knockout and the middle fraction is then inputted into a series of distillation columns that would further separate the products into the desired fractions.

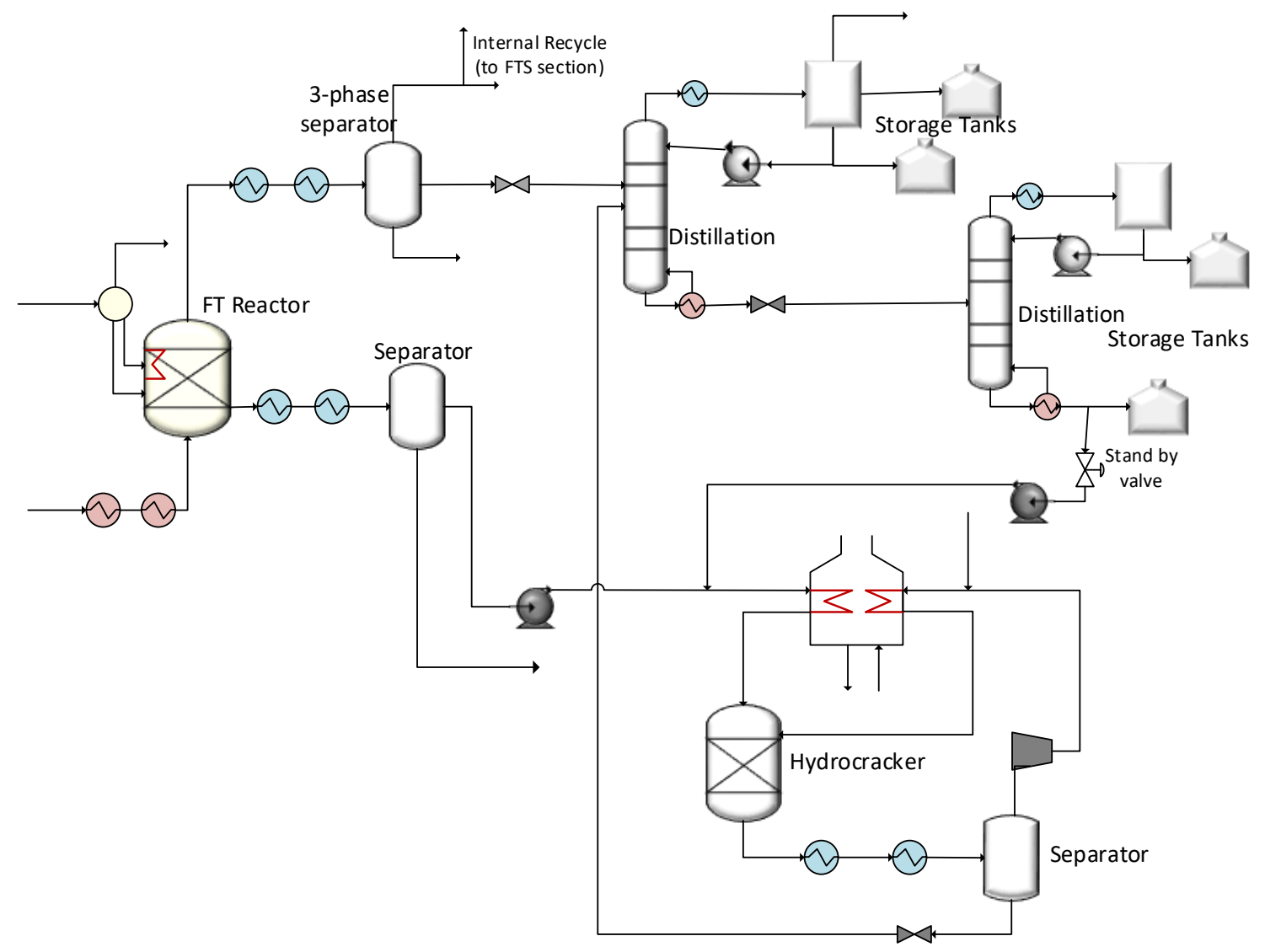

Figure 12: Another example of a conventional GTL plant setup

The following sections describe the simulated separation sequences using the two examples of the conventional GTL processes described previously as references. 


\subsection{1. $\quad$ Scenario 2: Separation of the Water First}

The second separation sequence (shown in Figure 13) flowsheet was constructed based on an existing GTL plant that utilizes a similar sequence to the FT products. It starts with cooling the FT products stream from a temperature of $240{ }^{\circ} \mathrm{C}$ to a temperature of $125^{\circ} \mathrm{C}$ since at that temperature and pressure, the three-phase separator would be able to separate the water effectively based on the properties of water.

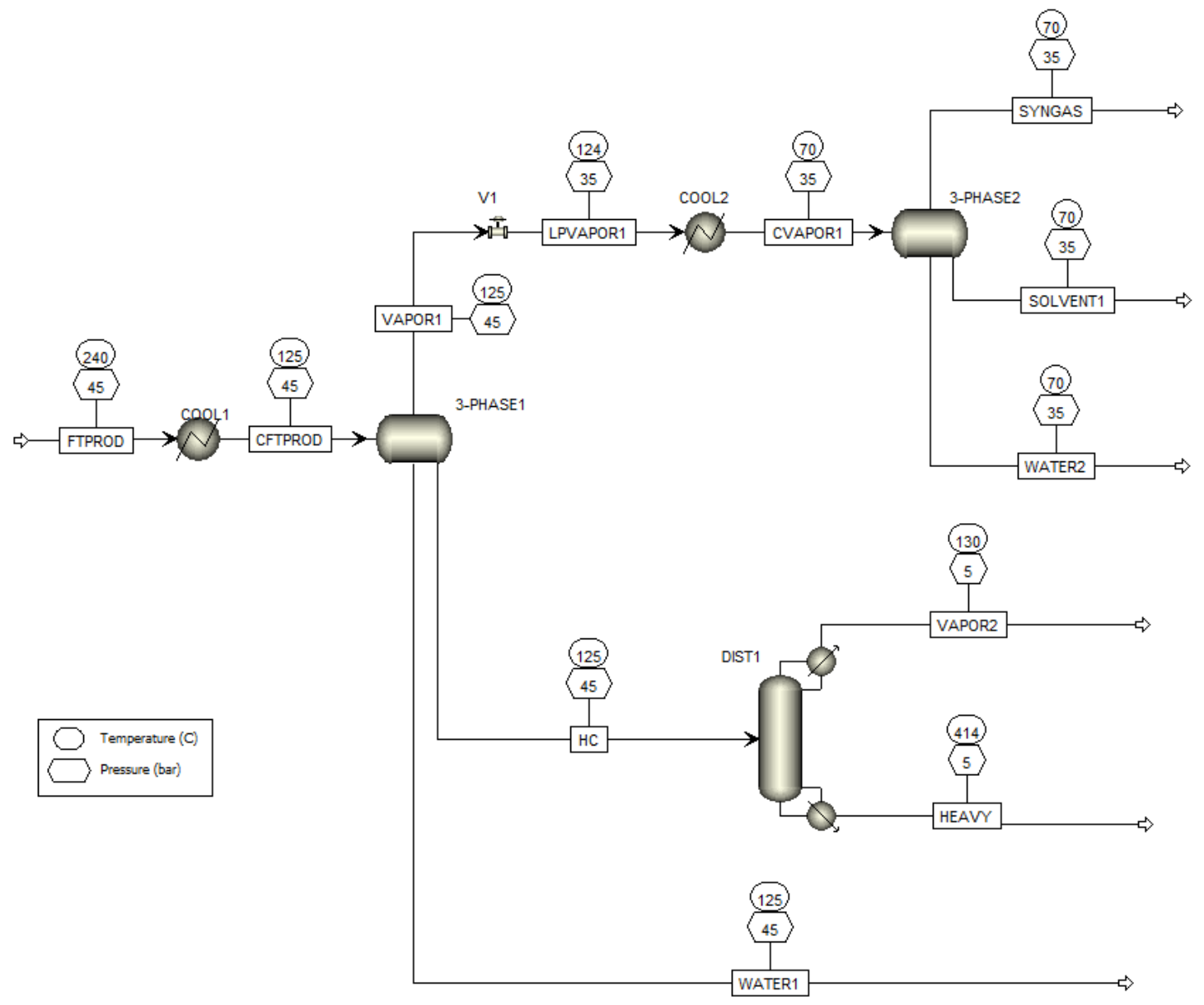

Figure 13: Scenario 2 Simulation Flowsheet 
In order to improve the recovery of the major components to be separated from 3-PHASE1, a sensitivity analysis was implemented. The design variables were the pressure and temperature at which the FTPROD stream needs to be fed into the threephase separator. The pressure was varied from 10-45 bar and the temperature was varied from $50-125{ }^{\circ} \mathrm{C}$ (since at higher temperatures, the water recovery would be $<80 \%$ until the three-phase separator would cease to separate the water as it would not be liquefied at the combination of higher temperatures and the inputted pressure range). The constraints taken into account were the recovery of water, the solvent, and the syngas. The sensitivity analysis showed that there needs to be a tradeoff between the recovery of water and that of $\mathrm{CO}$ since their relationship is inversely proportional. With increasing temperature, $\mathrm{CO}$ recovery increases while water recovery decreases. And with increasing pressure, $\mathrm{CO}$ recovery decreases while the water recovery increases. The solvent recovery shows a similar trend to that of water; however, the difference is very small and could be neglected for this purpose. From the sensitivity analysis results (shown in Figure 14-16), the 3-phase separator's operating conditions for this case were set to $125{ }^{\circ} \mathrm{C}$ and 45 bar. This lead to $95.16 \%$ of the syngas to be separated to the VAPOR1 stream, $85.51 \%$ of the water separated into the WATER1 stream, and $98.37 \%$ of the solvent $\mathrm{C}_{6}$ separated into the HC stream. 


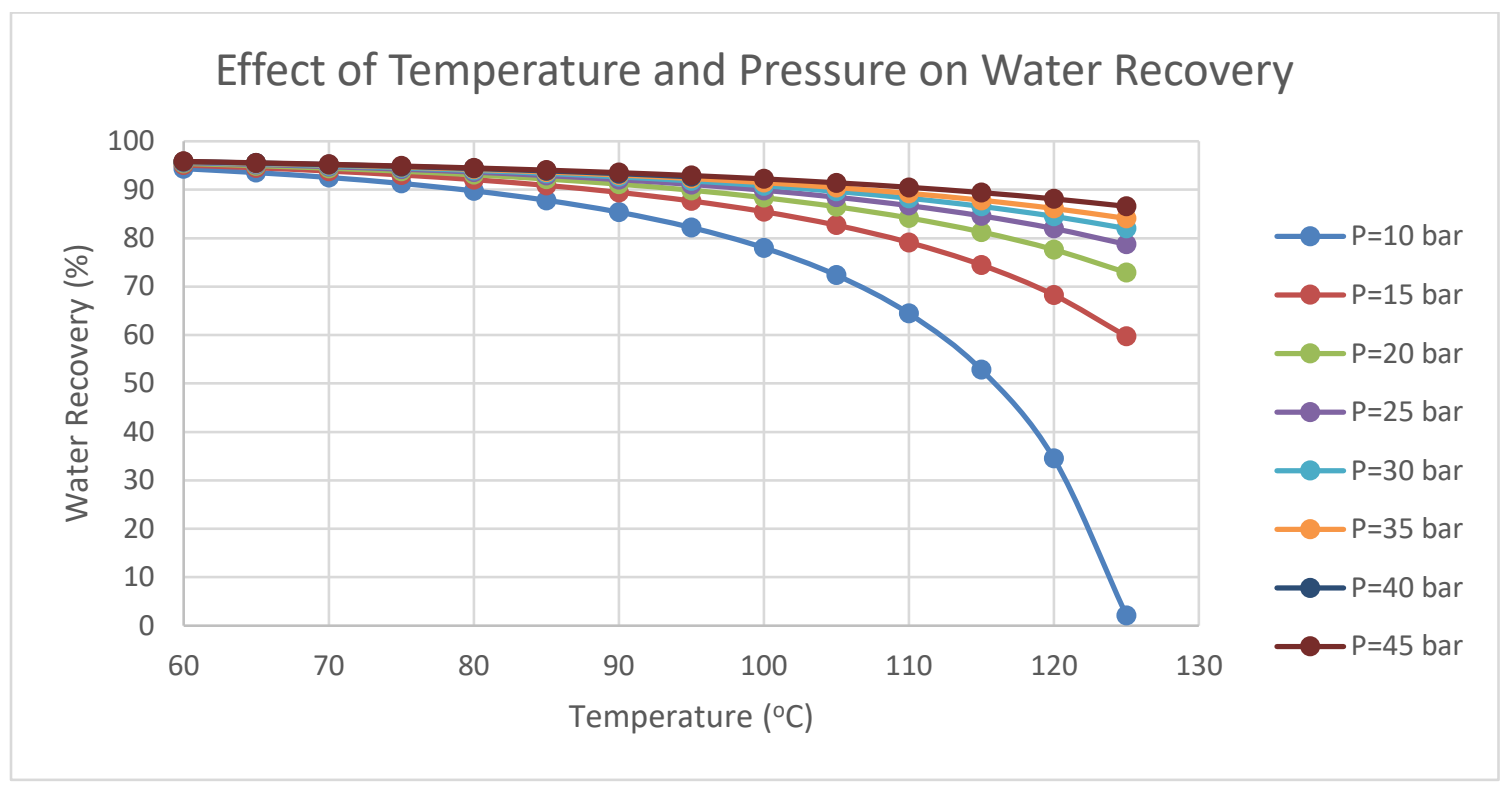

Figure 14: Effect of Temperature and Pressure on Water Recovery

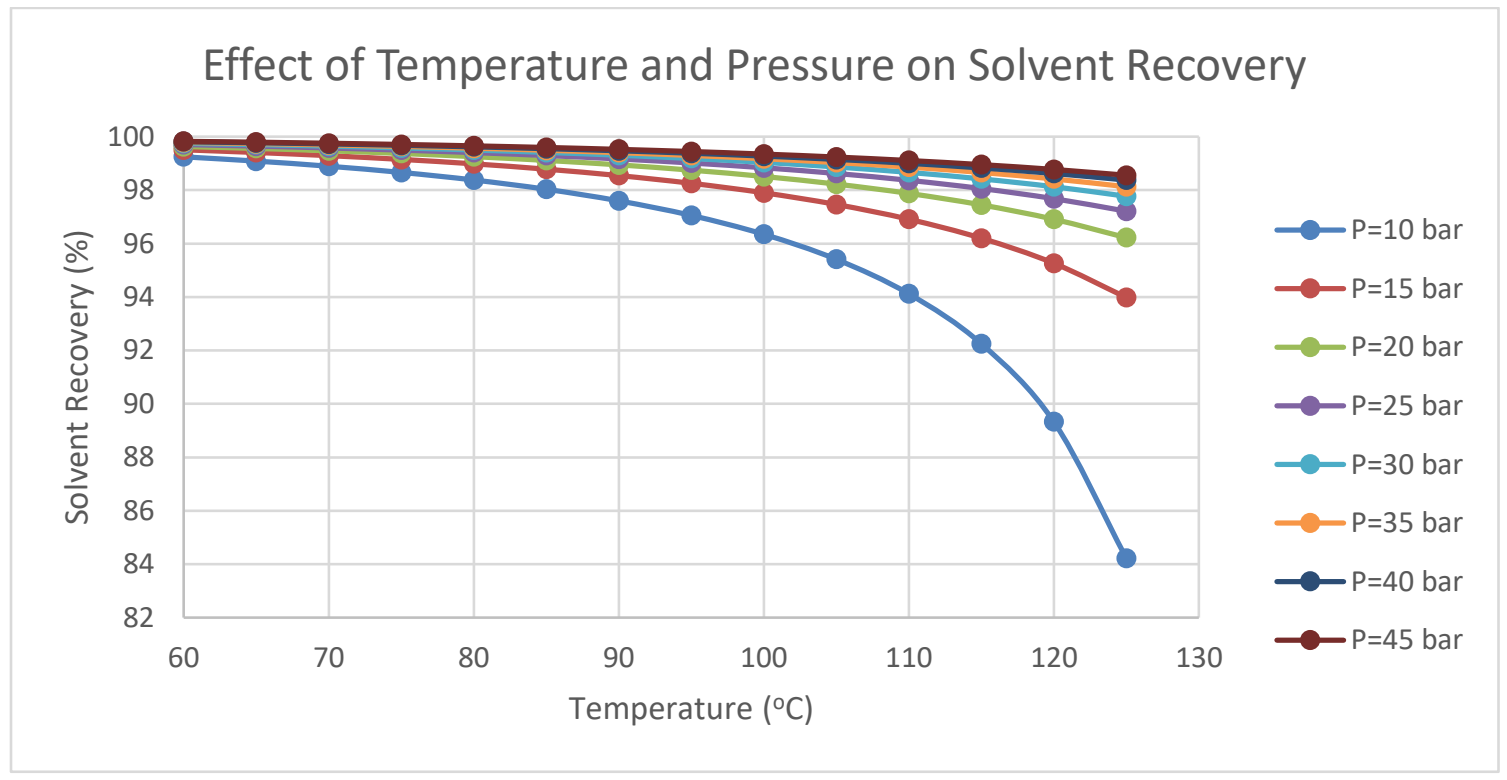

Figure 15: Effect of Temperature and Pressure on Solvent Recovery 


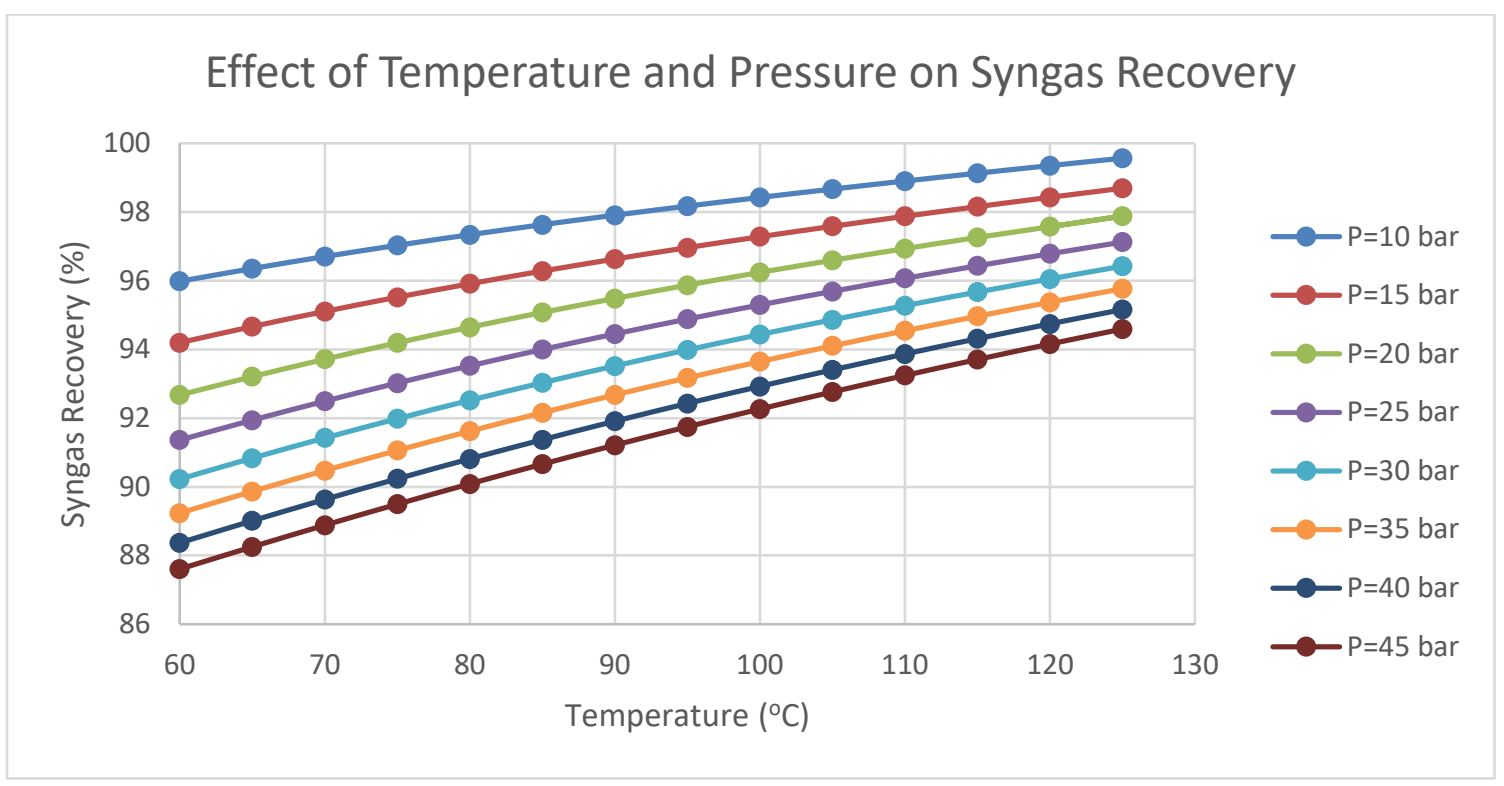

Figure 16: Effect of Temperature and Pressure on Syngas Recovery

The HC and VAPOR1 streams were then further separated to recover the rest of the products. The VAPOR1 stream's temperature and pressure were lowered to $70{ }^{\circ} \mathrm{C}$ and 35 bar before being inputted to another 3-phase separator, 3-PHASE2. This resulted in the separation of the remaining water and solvent in the gas stream.

The HC stream with the hydrocarbon products and most of the solvent were separated using a distillation column (DIST1) for efficient and maximum separation. Using a flash drum resulted in inefficient separation of the solvent and there was no condition in which the flash separation would result in an acceptable separation.

The distillation column optimized by performing a sensitivity analysis on the column. The design variables selected were:

- The molar reflux ratio

- The feed stage

The constraints were the following: 
- The solvent $\left(\mathrm{C}_{6}\right)$ recovery in the VAPOR2 stream

- The middle distillate and heavier components recovery (in this case, $\mathrm{C}_{7+}$ recovery was examined) in the HEAVY stream

While the optimization functions were:

- The reboiler duty

- The condenser duty

The distillation column, DIST1, was set to have 33 stages, with a pressure of 5 bar and the stage pressure drop for the column was set at 0.01 bar according to the allowable pressure drop in Parkash's book "Refining Processes Handbook" (Parkash, 2003). The column's operating specifications were set such that the feed stage was at 10 , the molar reflux ratio was 1.2 and the bottoms rate was $177 \mathrm{kmol} / \mathrm{hr}$ (since the $\mathrm{C}_{7+}$ products made up this quantity in the feed $\mathrm{HC}$ stream).

The second three-phase separator, 3-PHASE2, recovered the syngas from the other components in the VAPOR1 stream. The stream's pressure and temperature were lowered to 35 bar and $70^{\circ} \mathrm{C}$, respectively.

This separation sequence resulted in the recovery of $95 \%$ of the syngas, $94.85 \%$ of the heavy components $\left(\mathrm{C}_{7+}\right), 99.67 \%$ of the solvent, and $93.03 \%$ of the water. Table 12 and Table 13 tabulate the stream compositions and the components recovery, respectively. The net duties used in the process added up to be $1919 \mathrm{MW}$. The values are illustrated in Table 11. 
Table 11: Total Utilities for Scenario 2

\begin{tabular}{|l|l|l|}
\hline & Heating Utilities (MW) & Cooling Utilities (MW) \\
\hline COOL1 & - & -606.2 \\
\hline COOL2 & - & -8.824 \\
\hline 3-PHASE1 & - & -31.40 \\
\hline 3-PHASE2 & - & -3.190 \\
\hline DIST1 Condenser & - & -437.2 \\
\hline DIST1 Reboiler & 832.3 & - \\
\hline Total & 832.3 & -1087 \\
\hline
\end{tabular}


Table 12: Scenario 2 Stream Compositions

\begin{tabular}{|c|c|c|c|c|c|c|c|c|c|}
\hline Mole frac (\%) & FTPROD & VAPOR1 & $\mathrm{HC}$ & WATER1 & SYNGAS & SOLVENT1 & WATER2 & VAPOR2 & HEAVY \\
\hline Syngas & 7.189 & 77.34 & 0.3828 & 0.3667 & 95.02 & 0.8802 & 0.8495 & 0.3841 & 0 \\
\hline $\mathrm{H}_{2} \mathrm{O}$ & 7.089 & 6.882 & 0.4918 & 99.35 & 1.004 & 0.3212 & 99.09 & 0.4934 & 0 \\
\hline $\mathrm{C}_{1}-\mathrm{C}_{5}$ & 0.05236 & 0.08987 & 0.04954 & 0.03719 & 0.09376 & 0.07892 & 0.06081 & 0.04970 & 0 \\
\hline $\mathrm{C}_{6}$ & 85.38 & 15.68 & 98.75 & 0.01024 & 3.884 & 98.71 & 0.003632 & 99.07 & 0.08784 \\
\hline $\mathrm{C}_{7+}$ & 0.2914 & 0.001584 & 0.3256 & 0.2355 & 0.000111 & 0.01175 & 0 & 0.000596 & 99.912 \\
\hline
\end{tabular}

Table 13: Recovery of Scenario 2 Components in the Exit Streams

\begin{tabular}{|l|l|l|l|l|l|l|l|l|l|}
\hline Recovery (\%) & FTPROD & VAPOR1 & HC & WATER1 & SYNGAS & SOLVENT1 & WATER2 & VAPOR2 HEAVY & \\
\hline Syngas & - & - & - & 0.3113 & 94.96 & 0.1375 & 0.06356 & 4.530 \\
\hline $\mathrm{H}_{2} \mathrm{O}$ & - & - & - & 85.51 & 1.018 & 0.05086 & 7.517 & 5.900 & 0 \\
\hline $\mathrm{C}_{1}-\mathrm{C}_{5}$ & - & - & - & 4.334 & 12.87 & 1.692 & 0.6246 & 80.48 \\
\hline $\mathrm{C}_{6}$ & - & - & - & 0.000732 & 0.3268 & 1.298 & 0 \\
\hline $\mathrm{C}_{7+}$ & - & - & - & 4.931 & 0.002738 & 0.04528 & 0 \\
\hline
\end{tabular}




\subsection{2. $\quad$ Scenario 3: Separation of the Vapor and Liquid Components and Use of 3- phase Separator to Recover Water, Solvent, and Syngas}

As for the third separation sequence, the setup shown in Figure 12 was used as a reference for this design. The simulated flowsheet is as shown in Figure 17. The FT products stream enter a flash column (FC1) that would separate the vapors from the liquids at the conditions of $240{ }^{\circ} \mathrm{C}$ and 45 bar. However, with this initial setup, it was found that $51.2 \%$ of the heavy components were recovered in the vapor stream (VFTPROD) that was separated by FC1. Under those conditions, that is not typically the case and the heavy components would exist at the liquid phase. Moreover, using FC2 resulted in an inefficient separation of the heavy components from the remaining solvent. Thus, the flowsheet was modified (Figure 18). 


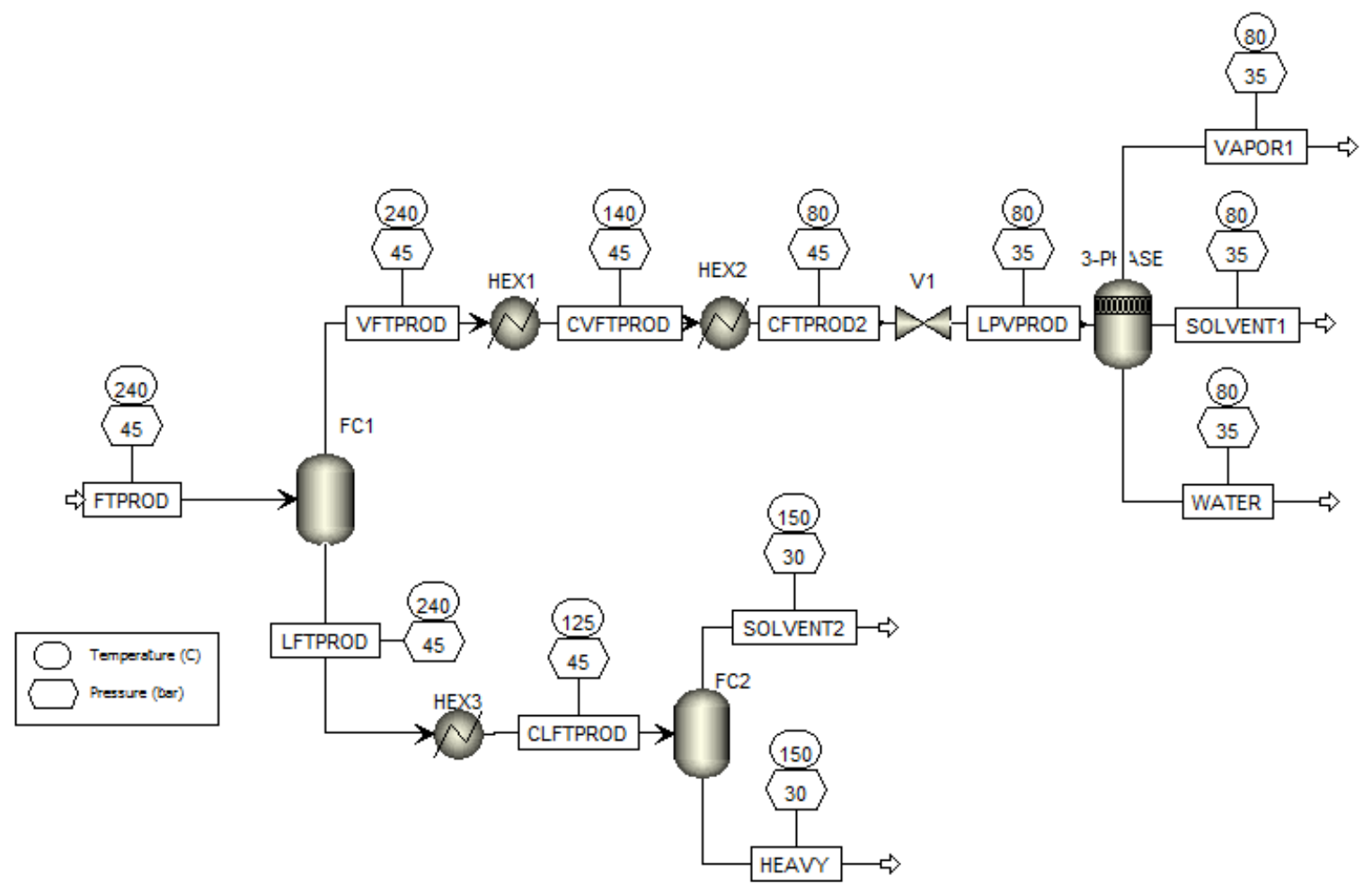

Figure 17: Scenario 3 Initial Simulation Flowsheet 


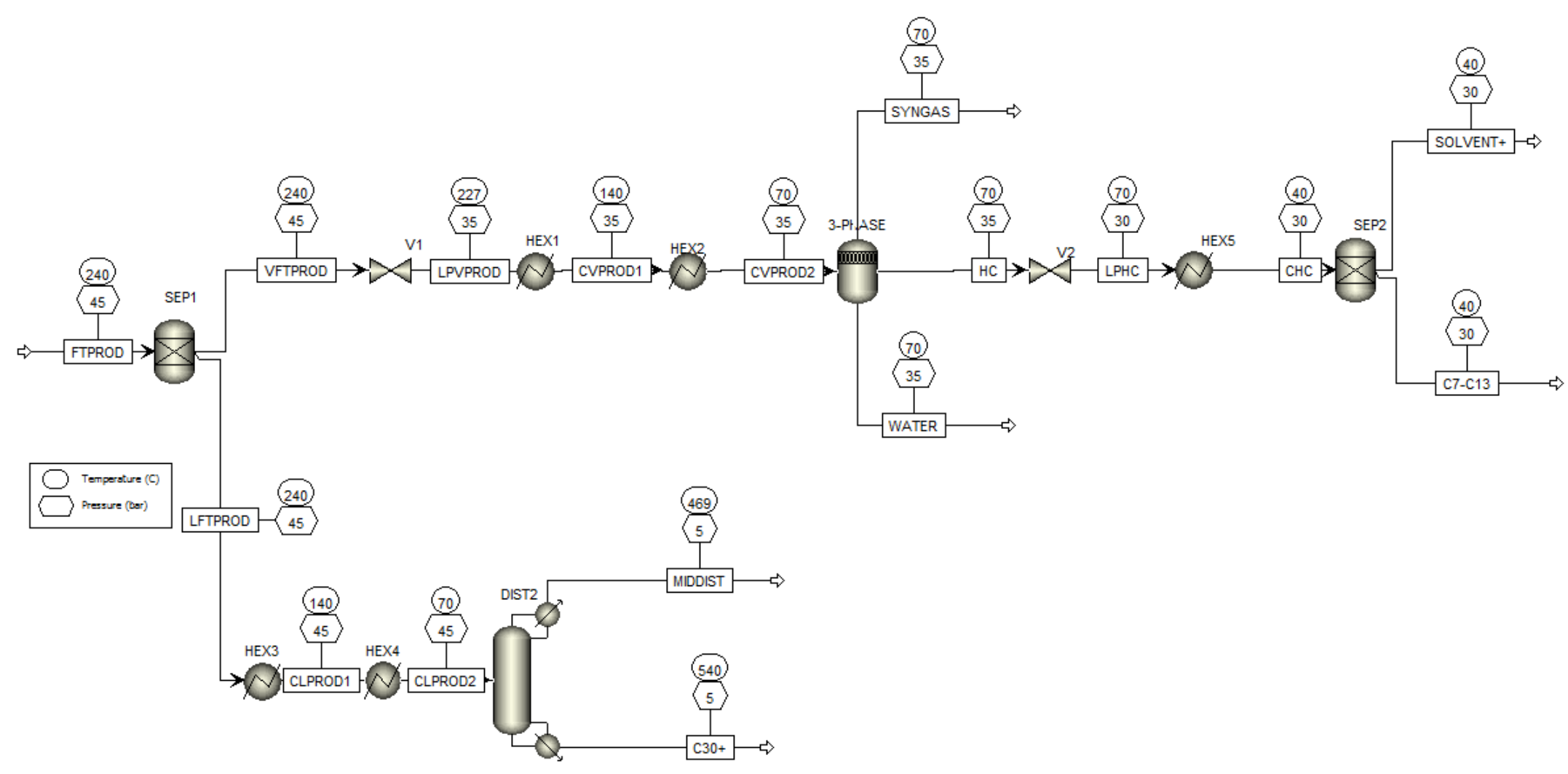

Figure 18: Scenario 3 Modified Simulation Flowsheet 
In order to separate the liquid and vapor components from the FT products stream, a component separator (SEP1) was used. The separator would separate the components based on split fractions. Therefore, it was assumed that the liquid stream composed of all components $\mathrm{C}_{14+}$ and their split fractions were set to 1 since that is typically what the liquid stream is composed of in the conventional process. This resulted in the recovery of $99.75 \%$ of the solvent, $99.3 \%$ of the water, and $99.2 \%$ of the syngas, and $99.9 \%$ of the heavy components. The stream compositions and the components recovered in the exit streams' data is shown in Table 14 and Table 15, respectively. The heating utilities amounted to $23.96 \mathrm{MW}$ while the cooling utilities were -947.3 MW. The net duties used in the process added up to be $971.26 \mathrm{MW}$. The values are illustrated in Table 16.

While the initial stages of this sequence resulted in a more realistic sense of having the liquid and vapor FT products in separate streams, the overall system does not seem sensible in a sense that can implemented as a real design. The equipment used in this separation sequence flowsheet have degrees of freedom that would allow the designer to select the most suitable technique to be implemented in place of the separators used in the simulation. 
Table 14: Scenario 3 Stream Compositions

\begin{tabular}{|c|c|c|c|c|c|c|c|c|c|c|}
\hline Mole frac (\%) & FTPROD & VFTPROD & LFTPROD & SYNGAS & $\mathrm{HC}$ & WATER & SOLVENT+ & C7-C13 & MIDDIST & $\mathrm{C} 30+$ \\
\hline Syngas & 7.19 & 7.21 & 0 & 95.1 & 0.74 & 0.71 & 0.74 & 0 & 0 & 0 \\
\hline $\mathrm{H} 2 \mathrm{O}$ & 7.09 & 7.11 & 0 & 1.00 & 0.32 & 99.2 & 0.32 & 0 & 0 & 0 \\
\hline $\mathrm{C} 1-\mathrm{C} 5$ & 0.05 & 0.05 & 0 & 0.06 & 0.05 & 0.04 & 0.05 & 0 & 0 & 0 \\
\hline C6 & 85.4 & 85.6 & 0 & 3.85 & 98.8 & 0 & 98.9 & 0 & 0 & 0 \\
\hline C7-C13 & 0.06 & 0.06 & 0 & 0 & 0.06 & 0 & 0 & 100 & 0 & 0 \\
\hline C14-C29 & 0.08 & 0 & 33.9 & 0 & 0 & 0 & 0 & 0 & 91.0 & 4.62 \\
\hline $\mathrm{C} 30+$ & 0.16 & 0 & 66.1 & 0 & 0 & 0 & 0 & 0 & 8.96 & 95.4 \\
\hline
\end{tabular}


Table 15: Recovery of Scenario 3 Components in Exit Streams

\begin{tabular}{|l|l|l|l|l|l|l|}
\hline Recovery (\%) & SYNGAS & WATER & SOLVENT+ & $\mathrm{C}_{7}-\mathrm{C}_{13}$ & MIDDIST & $\mathrm{C}_{30+}$ \\
\hline Syngas & 90.5 & 0.67 & 8.83 & 0 & 0 & 0 \\
\hline $\mathrm{H}_{2} \mathrm{O}$ & 0.97 & 95.2 & 3.83 & 0 & 0 & 0 \\
\hline $\mathrm{C}_{1}-\mathrm{C}_{5}$ & 7.33 & 5.29 & 87.4 & 0 & 0 & 0 \\
\hline $\mathrm{C}_{6}$ & 0.31 & 0 & 99.7 & 0 & 0 & 0 \\
\hline $\mathrm{C}_{7}-\mathrm{C}_{13}$ & 0.03 & 0 & 0 & 99.9 & 0 & 0 \\
\hline $\mathrm{C}_{14}-\mathrm{C}_{29}$ & 0 & 0 & 0 & 0 & 91.0 & 9.02 \\
\hline $\mathrm{C}_{30+}$ & 0 & 0 & 0 & 0 & 4.59 & 95.4 \\
\hline
\end{tabular}

Table 16: Total Utilities for Scenario 3

\begin{tabular}{|l|l|l|}
\hline & Heating Utilities (MW) & Cooling Utilities (MW) \\
\hline 3-PHASE & - & -8.542 \\
\hline DIST1 Condenser & - & -1.286 \\
\hline DIST1 Reboiler & 23.96 & - \\
\hline HEX1 & - & -523.3 \\
\hline HEX2 & - & -310.5 \\
\hline HEX3 & - & -4.331 \\
\hline HEX4 & - & -2.661 \\
\hline HEX5 & - & -96.66 \\
\hline Total & 23.96 & -947.3 \\
\hline
\end{tabular}


Table 17 shows the percent recovered for each of the major components: the syngas, solvent, water and heavy components in each of the simulated scenarios. It can be seen that Scenario 3 resulted in the highest recovery.

Comparing the energy consumption of the three scenarios (shown in Table 18), it can be noted that Scenario 3 had the least energy consumption of the three separation sequences.

Table 17: Recovery of the Components for each Design

\begin{tabular}{|l|l|l|l|}
\hline Recovery (\%) & Scenario 1 & Scenario 2 & Scenario 3 \\
\hline Syngas & $95.6 \%$ & $95 \%$ & $99.2 \%$ \\
\hline Solvent & $99.95 \%$ & $99.67 \%$ & $99.75 \%$ \\
\hline Water & $99.7 \%$ & $93.03 \%$ & $99.3 \%$ \\
\hline Heavy Components & $93.5 \%$ & $94.85 \%$ & $99.9 \%$ \\
\hline
\end{tabular}

Table 18: Comparison of the Energy Consumed for each Scenario

\begin{tabular}{|l|l|l|l|}
\hline & Scenario 1 & Scenario 2 & Scenario 3 \\
\hline Heating Utilities (MW) & 574.6 & 832.3 & 23.96 \\
\hline Cooling Utilities (MW) & -1227 & -1087 & -947.3 \\
\hline Total Utilities (MW) & 1802 & 1919 & 971.3 \\
\hline
\end{tabular}

Considering the design simplicity, it was shown that separating the water at the earlier stages of the separation (Scenarios 2 and 3) resulted in fewer separation equipment as compared to Scenario 1 where the water was carried on to the end. While 
Scenario 2 showed the highest energy consumption and a reasonable amount of products recovered, it should be noted that this design is the closest to what is implemented commercially. Scenario 1 lacks equipment that would control the streams' conditions prior to the flash columns and distillation column - which would affect the energy requirements data obtained. Scenario 3 is open to suggestions to replace the separators that are used in the simulation when it is to be selected as the method of separation.

A comparison was then made to determine the energy consumption of Scenario 3 with and without the use of the solvent. Using the same amount of syngas that was used for the reaction, the ASF product distribution calculations were then made. The FT products stream data was inputted into the separation sequence with the same setup as Scenario 3 but at an inlet temperature of $240{ }^{\circ} \mathrm{C}$ and 24 bar, respectively.

Table 19: Comparing Scenario 3 energy consumption with and without solvent

\begin{tabular}{|l|l|l|}
\hline & Scenario 3 with solvent & Scenario 3 without solvent \\
\hline Heating Utilities (MW) & 23.9 & 17.6 \\
\hline Cooling Utilities (MW) & 947.4 & 78.5 \\
\hline Total Utilities (MW) & 971.3 & 96.9 \\
\hline \multicolumn{2}{|l|}{} \\
\hline Molar Flowrate (kmol/hr) & 63,983 & 15,996 \\
\hline Mass Flowrate (kg/hr) & $4,894,570$ & 289,000 \\
\hline
\end{tabular}


The data tabulated in Table 19 shows that the energy consumption is higher with the SCF-FT synthesis since with the addition of the solvent at a solvent to syngas molar ratio of $3: 1$, the molar flowrate would be four times that without the solvent. Therefore, the larger flowrate results in larger energy requirements since the heat exchanger duties are a function of the flowrates. Further studies need to be conducted to determine the economic evaluation of an SCF-FT products separation as it is already known that the application of an SCF-FT process leads to improved thermal management of the reactor, longer life of the catalyst, and products selectivity control. 


\section{CONCLUSION AND FUTURE WORK}

The application of supercritical fluid (SCF) solvents have emerged from extensive research due to the limitations faced with the media used in conventional Fischer-Tropsch synthesis. The benefits of using a SCF owe to its properties that possess high diffusivity (relative to the liquid phase in the slurry reactor), better heat transfer control (relevant to the gas phase reaction in multitubular fixed bed reactor) and improved solubility of the solvent in the hydrocarbon products (compared to both technologies). While the previous research focused mainly on the first two sections of the GTL process: the syngas production and the FT process, fewer studies have looked at the advancements in the FT products separation when utilizing the supercritical solvents in the reaction.

This work is an extension to the less studied field of SCF-FT product separation. It covers another method for separating water from the solvent and products at the earlier stages of the separation prior to the medium and heavy hydrocarbons. Removing the water at later stages would result in a larger treatment capacity and larger flowrates along the process. Therefore, by utilizing heuristics and looking at the feasible options to approach the SCF-FT products separation (removing the heavy components first and removing the water first), three separation sequence designs were developed and simulated using Aspen Plus ${ }^{\circledR}$. For each separation sequence the analysis on energy consumption, products recovery, and the design simplicity were used as parameters for comparison. The results showed that Scenario 1 was a more complicated design than 
Scenarios 2 and 3 as it had more equipment and an extra distillation column which adds to the costs of the process. While Scenario 2 flowsheet is the closest when comparing the sequence to a commercial one, Scenario 3 showed the least energy requirements and the highest products recovery while also offering the designer to select the most suitable equipment in place of the separators used.

The suggestions listed below are recommended for future work:

- Incorporating a recycle stream to make use of the unreacted syngas by recycling it back to the syngas production unit of the GTL process.

- Performing heat integration between the entire GTL process to evaluate and integrate the energy consumption of the process as a whole.

- Determining the effects of using another solvent to the products separation sequence.

- Evaluating the economic analysis for the implementation of the SCF-FT process. 


\section{REFERENCES}

Arora, S. and Prasad, R. (2016) 'An overview on dry reforming of methane: strategies to reduce carbonaceous deactivation of catalysts', RSC Advances. Royal Society of Chemistry, 6, pp. 108668-108688. doi: 10.1039/C6RA20450C.

Aspen Technology (2013) 'Aspen Physical Property System', aspentech. Available at: http://home.aspentech.com/products/pages/aspen-properties.

Aspen Technology (2017) Design and Optimize Chemical Processes with Aspen Plus®, aspentech. Available at: http://www.aspentech.com/products/aspen-plus/ (Accessed: 8 March 2017).

Bao, B. et al. (2012) 'Elevated Pressure Supercritical Fischer-Tropsch Synthesis:

Product Separation and Energy Integration', in The proceedings of the 2012 International Symposium of Supercritical Fluids (ISSF), p. San Fransisco, California. Bao, B. (2012) 'Process Design and Optimization of Biorefining Pathways', Texas A\&M University, (Ph.D. Dissertation).

Bao, B., El-Halwagi, M. M. and Elbashir, N. O. (2010) 'Simulation, integration, and economic analysis of gas-to-liquid processes', Fuel Processing Technology. Elsevier B.V., 91(7), pp. 703-713. doi: 10.1016/j.fuproc.2010.02.001.

Cano-Ruiz, J. a. and McRae, G. J. (1998) 'Environmentally Conscious Chemical Process Design', Annual Review of Energy and the Environment, 23, pp. 499-536. doi:

10.1146/annurev.energy.23.1.499.

Challiwala, M. S. et al. (2017) 'A combined thermo-kinetic analysis of various methane 
reforming technologies: Comparison with dry reforming', Journal of CO2 Utilization. Elsevier Ltd., 17, pp. 99-111. doi: 10.1016/j.jcou.2016.11.008.

Choi, G. N. et al. (1997) 'Design and economics of a Fischer-Tropsch plant for converting natural gas to liquid transportation fuels', ACS Division of Fuel Chemistry, Preprints, 42(2), pp. 667-670. doi: 10.1016/S0140-6701(97)84578-X.

Dancuart, L. P. and Steynberg, A. P. (2007) Fischer-Tropsch based GTL technology: a new process?, Studies in Surface Science and Catalysis. Elsevier B.V. doi:

10.1016/S0167-2991(07)80490-3.

de Klerk, A. (2007) 'Environmentally friendly refining: Fischer-Tropsch versus crude oil', Green Chemistry, 9(6), p. 560. doi: 10.1039/b614187k.

de Klerk, A. (2011) 'Sasol 1 Facility', In: Fischer-Tropsch Refining. Wiley-VCH, pp. 153-180. Available at: http://dx.doi.org/10.1002.9783527635603.ch8.

Dry, M. E. (2002) 'The Fischer-Tropsch process: 1950-2000', Catalysis Today, 71(3-4), pp. 227-241. doi: 10.1016/S0920-5861(01)00453-9.

EIA (2016) 'World energy demand and economic outlook EIA's handling of non-U.S. policies in the International Energy Outlook', U.S. Energy Information Administration, 2016(May 2015), pp. 7-17. Available at: http://www.eia.gov/forecasts/ieo/world.cfm. Elbashir, N. O. et al. (2005) 'Impact of cobalt-based catalyst characteristics on the performance of conventional gas-phase and supercritical-phase Fischer - Tropsch synthesis', Applied Catalysis A: General, 285, pp. 169-180. doi:

10.1016/j.apcata.2005.02.023.

Elbashir, N. O. et al. (2010) 'Advancement of Fischer-Tropsch Synthesis via Utilization 
of Supercritical Fluid Reaction Media', AIChE J., 56(4), pp. 997-1015. doi: 10.1002/aic. Elbashir, N. O., Bao, B. and El-halwagi, M. M. (2009) 'An Approach to the Design of Advanced Fischer- Tropsch Reactor for Operation in Near-Critical and Supercritical Phase Media', Advances in Gas Processing, 1(October 2015), pp. 423-433. doi: 10.1016/B978-0-444-53292-3.50051-1.

Elbashir, N. O. M. (2013) Fundamentals and Design of the Supercritical Fluids Fischer Tropsch, LAP LAMBERT Academic Publishing.

Elbashir, N. O. and Roberts, C. B. (2005) 'Catalyst in Near-Critical and Supercritical Hexane Media', Industrial \& Engineering Chemistry Research, 44, pp. 505-521. Elmalik, E. E. et al. (2011) 'Solvent selection for commercial supercritical FischerTropsch synthesis process', Fuel Processing Technology. Elsevier B.V., 92(8), pp. 1525-1530. doi: 10.1016/j.fuproc.2011.03.014.

Fan, L. and Fujimoto, K. (1999) 'Fischer - Tropsch synthesis in supercritical fluid : characteristics and application', Applied Catalysis A: General, 186, pp. 343-354. Fischer, F. and Tropsch, H. (1926) 'The synthesis of petroleum at atmospheric pressures from gasification products of coal', Brennstoff- Chemie, pp. 97-104.

Förtsch, D., Pabst, K. and Groß-Hardt, E. (2015) 'The product distribution in FischerTropsch synthesis: An extension of the ASF model to describe common deviations', Chemical Engineering Science. Elsevier, 138, pp. 333-346. doi: 10.1016/j.ces.2015.07.005.

Gabriel, K. J. et al. (2014) 'Targeting of the water-energy nexus in gas-to-liquid processes: A comparison of syngas technologies', Industrial and Engineering Chemistry 
Research, 53(17), pp. 7087-7102. doi: 10.1021/ie4042998.

Hao, X. et al. (2008) 'Simulation analysis of a gas-to-liquid process using aspen plus', Chemical Engineering and Technology, 31(2), pp. 188-196. doi:

10.1002/ceat.200700336.

Khodakov, A. Y., Chu, W. and Fongarland, P. (2007) 'Advances in the Development of Novel Cobalt Fischer - Tropsch Catalysts for Synthesis of Long-Chain Hydrocarbons and Clean Fuels', pp. 1692-1744.

Kim, Y. H. et al. (2009) 'A simulation study on gas-to-liquid (natural gas to FischerTropsch synthetic fuel) process optimization', Chemical Engineering Journal, 155(1-2), pp. 427-432. doi: 10.1016/j.cej.2009.08.018.

Malek, N. and Glavic, P. (1994) 'Theoretical bases of separation sequence heuristics', Computers and Chemical Engineering, 18(SUPPL), pp. 0-4. doi: 10.1016/00981354(94)80024-3.

Malek Abbaslou, R. M., Soltan Mohammadzadeh, J. S. and Dalai, A. K. (2009) 'Review on Fischer-Tropsch synthesis in supercritical media', Fuel Processing Technology.

Elsevier B.V., 90(7-8), pp. 849-856. doi: 10.1016/j.fuproc.2009.03.018.

Noureldin, M. M. B. et al. (2015) 'A process integration approach to the assessment of $\mathrm{CO} 2$ fixation through dry reforming', ACS Sustainable Chemistry and Engineering, 3(4), pp. 625-636. doi: 10.1021/sc5007736.

Noureldin, M. M. B., Elbashir, N. O. and El-Halwagi, M. M. (2014) 'Optimization and selection of reforming approaches for syngas generation from natural/shale gas', Industrial and Engineering Chemistry Research, 53(5), pp. 1841-1855. doi: 
10.1021/ie402382w.

Panahi, M. et al. (2012) 'A Natural Gas to Liquids Process Model for Optimal Operation', Ind. Eng. Chem. Res, 51, pp. 425-433. doi: 10.1021/ie2014058.

Parkash, S. (2003) Refining Processes Handbook. Burlington: Gulf Professional Publishing. doi: 10.1016/B978-0-7506-7721-9.50022-0.

Sie, S. T. and Krishna, R. (1999) 'Fundamentals and selection of advanced FischerTropsch reactors', Applied Catalysis A: General, 186(1-2), pp. 55-70. doi:

10.1016/S0926-860X(99)00164-7.

Speight, J. G. (2007) Natural Gas: A Basic Handbook. Gulf Publishing Company, Houston.

Steynberg (2004) Introduction to Fischer-Tropsch technology, Studies in Surface Science and Catalysis. Elsevier B.V. doi: 10.1016/S0167-2991(04)80458-0.

Steynberg, A. P. et al. (2004) 'Chapter 2 - Fischer-Tropsch Reactors', in Studies in Surface Science and Catalysis, pp. 64-195. doi: 10.1016/S0167-2991(04)80459-2.

Stranges, A. N. (2007) A history of the fischer-tropsch synthesis in Germany 1926-45, Studies in Surface Science and Catalysis. Elsevier B.V. doi: 10.1016/S01672991(07)80469-1.

van der Laan, G. P. (1999) Kinetics, Selectivity and Scale Up of the Fischer-Tropsch Synthesis, University of Groningen. doi: 10.1081/CR-100101170.

Vosloo, A. C. (2001) 'Fischer-Tropsch: A futuristic view', Fuel Processing Technology, 71(1-3), pp. 149-155. doi: 10.1016/S0378-3820(01)00143-6.

Wilhelm, D. J. et al. (2001) 'Syngas production for gas-to-liquids applications: 
Technologies, issues and outlook', Fuel Processing Technology, 71(1-3), pp. 139-148. doi: 10.1016/S0378-3820(01)00140-0.

Yan, Y. et al. (2014) 'Effect of Catalytic Cylinders on Autothermal Reforming of Methane for Hydrogen Production in a Microchamber Reactor', The Scientific World Journal, 2014, pp.1-9. doi:10.1155/2014/451919.

Yokota, K., Hanakata, Y. and Fujimoto, K. (1990) 'Supercritical phase Fischer-Tropsch synthesis', Chemical Engineering Science, 45(8), pp. 2743-2749. doi: 10.1016/00092509(90)80166-C. 


\section{APPENDICES}

\section{Appendix A: SCF-FT Products Stream Data for Simulations Input}

The following table shows the SCF-FT products stream data that was used as input to the simulations (Elbashir, Bao and El-halwagi, 2009).

\begin{tabular}{|c|c|}
\hline Component & Mole Flow (kmol/hr) \\
\hline $\mathrm{CO}$ & 1244 \\
\hline H2 & 3355 \\
\hline H2O & 4536 \\
\hline C1 & 7.26 \\
\hline $\mathbf{C 2}$ & 6.97 \\
\hline C3 & 6.69 \\
\hline C4 & 6.42 \\
\hline $\mathbf{C 5}$ & 6.16 \\
\hline C6 & $5.46 * 10^{4}$ \\
\hline $\mathbf{C 7}$ & 5.68 \\
\hline C8 & 5.45 \\
\hline C9 & 5.24 \\
\hline C10 & 5.03 \\
\hline C11 & 4.83 \\
\hline $\mathbf{C 1 2}$ & 4.63 \\
\hline $\mathbf{C 1 3}$ & 4.45 \\
\hline C14 & 4.27 \\
\hline C15 & 4.10 \\
\hline C16 & 3.93 \\
\hline $\mathbf{C 1 7}$ & 3.78 \\
\hline C18 & 3.63 \\
\hline C19 & 3.48 \\
\hline $\mathrm{C20}$ & 3.34 \\
\hline C21 & 3.21 \\
\hline $\mathbf{C 2 2}$ & 3.08 \\
\hline $\mathrm{C23}$ & 2.96 \\
\hline $\mathrm{C24}$ & 2.84 \\
\hline $\mathrm{C25}$ & 2.73 \\
\hline C26 & 2.62 \\
\hline
\end{tabular}




\begin{tabular}{|l|l|}
\hline C27 & 2.51 \\
\hline C28 & 2.41 \\
\hline C29 & 2.31 \\
\hline C30 & 99.97 \\
\hline Total Flow (kmol/hr) & $6.40 * 10^{4}$ \\
\hline Total Flow (kg/hr) & $4.90 * 10^{6}$ \\
\hline Temperature $\left.\mathbf{~}^{\mathbf{0}} \mathbf{C}\right)$ & 240 \\
\hline Pressure $($ bar $)$ & 45 \\
\hline
\end{tabular}




\section{Appendix B: The Anderson-Schulz-Flory product distribution model calculations}

The FT products distribution calculations were performed to determine the ASF product distribution of the Fischer-Tropsch process with the following conditions:

- The chain growth probability factor, $\alpha=0.96$

- a feed $\mathrm{H}_{2}$ to $\mathrm{CO}$ molar ratio of 2.15:1

- a solvent to syngas ratio of 3:1

- $\quad$ solvent used was $\mathrm{C}_{6}$

- $73 \% \mathrm{CO}$ conversion

- Basis CO mole flow was $100 \mathrm{~mol} / \mathrm{s}$

In order to calculate the ASF distribution, the subsequent steps were made.

Step 1

Equation ( 7 ) below was used to calculate the mole fraction of a chain of length $n$.

$$
X_{n}=\alpha^{n-1}(1-\alpha)
$$

Step 2

The weight fraction of a chain of length $n, \mathrm{~W}_{\mathrm{n}}$, was calculated using the following equation:

$$
W_{n}=n \alpha^{n-1}(1-\alpha)^{2}
$$

Step 3

The number of moles of the hydrocarbon products, $n_{C n H 2 n+2}$, was determined by dividing the weight fraction, $\mathrm{W}_{\mathrm{n}}$, by the molecular weight.

$$
n_{C_{n} H_{2 n+2}}=\frac{W_{n}}{\text { Molecular Weight }}
$$


Step 4

After finding the number of moles $n_{\mathrm{CnH} 2 n+2}$, the amount of $\mathrm{CO}, n_{\mathrm{CO}}$, corresponding to each mole of $\mathrm{C}_{n} \mathrm{H}_{2 n+2}$ produced was calculated using equation ( 10 ).

$$
n_{C O}=n_{C_{n} H_{2 n+2}} * n
$$

Using the calculations made for the ASF distribution, the reaction specifications were used to determine the number of reactants and products for the FT reaction,

$$
a \mathrm{CO}+b \mathrm{H}_{2} \rightarrow x \mathrm{C}_{n} \mathrm{H}_{2 n+2}+y \mathrm{H}_{2} \mathrm{O}
$$

The following calculations were made:

Step 5

The number of moles of $\mathrm{CO}$ reacted, $n_{C O \text {,reacted }}$, were calculated by using the following equation.

$$
n_{C O, \text { reacted }}=n_{C O} * \frac{X_{C O} * 100}{\sum n_{C O}}
$$

Step 6

The number of moles of $\mathrm{C}_{\mathrm{n}} \mathrm{H}_{2 \mathrm{n}+2}$ produced were then determined using equation ( 12 ).

$$
n_{C_{n} H_{2 n+2}, \text { produced }}=n_{C_{n} H_{2 n+2}} * \frac{X_{C O} * 100}{\sum n_{C O}}
$$

Step 7

The number of moles of $\mathrm{H}_{2}$ reacted, $n_{H 2}$, reacted, were also found.

$$
n_{H_{2}, \text { reacted }}=2 n_{C O, \text { reacted }}+n_{C_{n} H_{2 n+2}, \text { produced }}
$$


Step 8

Since the ratio of the number of moles of $\mathrm{CO}$ reacted to the number of moles of $\mathrm{H}_{2} \mathrm{O}$ produced is $1: 1$,

$$
n_{\mathrm{H}_{2} \mathrm{O}, \text { produced }}=n_{\mathrm{CO}, \text { reacted }}
$$

Step 9

The mass of $\mathrm{C}_{n} \mathrm{H}_{2 \mathrm{n}+2}$ produced was then calculated.

$$
m_{C_{n} H_{2 n+2}, \text { produced }}=n_{C_{n} H_{2 n+2}, \text { produced }} * M W
$$

Step 10

The mole fraction of $\mathrm{CO}$ reacted was determined using the following.

$$
X_{C O}=\frac{n_{C O, \text { reacted }}}{75}
$$

Step 11

The fractional conversion was then found using the equation below.

$$
\text { Fractional conversion }=\frac{n_{C O, \text { reacted }}}{n_{C O, \text { total }}}
$$


Appendix C: Scenario 1 Simulation Stream Results

The following table shows the stream results obtained from running Scenario 1's simulation on Aspen Plus.

\begin{tabular}{|c|c|c|c|c|c|c|c|c|c|c|c|c|c|c|c|c|}
\hline $\begin{array}{l}\text { Mole Flow } \\
\text { (kmol/hr) }\end{array}$ & FTPROD & \begin{tabular}{|l|} 
VPROD1 \\
\end{tabular} & LPROD1 & \begin{tabular}{|l|} 
VPROD2 \\
\end{tabular} & \begin{tabular}{|l|} 
LPROD2 \\
\end{tabular} & VPROD3 & LPROD3 & VAPOR & HEAVY & SOLVENT1 & PERGAS1 & WATER1 & SOLVENT2 & PERGAS2 & WATER2 & SOLVENT3 \\
\hline $\mathrm{CO}$ & 1,244 & 1,219 & 25.05 & \begin{tabular}{|l|}
0.060 \\
\end{tabular} & 24.99 & 5.153 & 19.84 & 19.84 & 0 & 0 & 1,005 & 0.153 & 103.2 & 37.19 & 97.54 & 1.517 \\
\hline H2 & 3,355 & 3,355 & 0.042 & \begin{tabular}{|l|l|}
0.034 \\
\end{tabular} & 0.008 & 0.008 & 0 & 0 & 0 & 0 & 3,355 & 0 & 0 & 0.001 & 0 & 0 \\
\hline $\mathrm{H} 2 \mathrm{O}$ & 4,536 & 4,452 & 83.73 & \begin{tabular}{|l|l|}
0.183 \\
\end{tabular} & 83.54 & 15.24 & 68.30 & 68.30 & 0 & 0 & 2.700 & 10.56 & 9.350 & 0.068 & 4,513 & 0.177 \\
\hline C1 & 7.257 & 6.669 & 0.589 & 0 & 0.589 & 0.032 & 0.557 & 0.557 & 0 & 0 & 3.130 & 0.002 & 2.019 & 0.179 & 1.909 & 0.019 \\
\hline C2 & 6.967 & 4.051 & 2.916 & 0 & 2.916 & 0.018 & 2.898 & 2.898 & 0 & 0 & \begin{tabular}{|l|l|}
1.090 \\
\end{tabular} & 0.002 & 2.963 & 0.090 & 2.802 & 0.020 \\
\hline C3 & 6.689 & 3.809 & 2.879 & 0 & 2.879 & 0.015 & 2.864 & 2.864 & 0 & 0 & 0.235 & 0.002 & 3.295 & 0.027 & 3.114 & 0.016 \\
\hline C4 & 6.421 & 3.577 & 2.844 & 0 & 2.844 & 0.013 & 2.831 & 2.831 & 0 & 0 & \begin{tabular}{|l|}
0.028 \\
\end{tabular} & 0 & 3.292 & 0.007 & 3.085 & 0.008 \\
\hline C5 & 6.164 & 3.267 & 2.897 & 0 & 2.897 & 0.011 & 2.886 & 2.886 & 0 & 1.551 & \begin{tabular}{|l|}
0.053 \\
\end{tabular} & 0 & \begin{tabular}{|l|l}
4.499 \\
\end{tabular} & 0.002 & 0 & 0.059 \\
\hline C6 & 54,628 & 26,514 & 28,113 & 0.921 & 28,112 & 85.91 & 28,027 & 28,024 & 2.489 & 49,876 & 26.32 & 0 & 4620 & 0.650 & 0.092 & \begin{tabular}{ll|}
101.7 \\
\end{tabular} \\
\hline C7 & 5.681 & 2.396 & 3.285 & 0 & 3.285 & 0.007 & 3.278 & 1.095 & 2.183 & 3.492 & 0 & 0 & 0.005 & 0 & 0 & 0 \\
\hline C8 & 5.454 & 1.370 & 4.083 & 0 & 4.083 & 0.004 & 4.079 & 0.022 & 4.057 & 1.397 & 0 & 0 & 0 & 0 & 0 & 0 \\
\hline C9 & 5.235 & 1.647 & 3.589 & 0 & 3.589 & 0.004 & 3.584 & 0.006 & 3.578 & 1.658 & 0 & 0 & 0 & 0 & 0 & 0 \\
\hline C10 & 5.026 & 1.354 & 3.672 & 0 & 3.671 & 0.003 & 3.668 & 0 & 3.668 & 1.358 & 0 & 0 & 0 & 0 & 0 & 0 \\
\hline C11 & 4.825 & 1.005 & 3.820 & 0 & 3.820 & 0.002 & 3.818 & 0 & 3.818 & 1.007 & 0 & 0 & 0 & 0 & 0 & 0 \\
\hline C12 & 4.632 & 0.768 & 3.864 & 0 & 3.864 & 0.002 & 3.862 & 0 & 3.862 & 0.770 & 0 & 0 & 0 & 0 & 0 & 0 \\
\hline C13 & 4.447 & 0.610 & 3.837 & $\mid$\begin{tabular}{l|l|} 
\\
\end{tabular} & 3.837 & 0.001 & 3.836 & 0 & 3.836 & 0.611 & $\mid$\begin{tabular}{l|l|} 
\\
\end{tabular} & 0 & $\mid$\begin{tabular}{l|l|} 
\\
\end{tabular} & 0 & 0 & 0 \\
\hline C14 & 4.269 & 0.467 & 3.801 & $\mid 0$ & 3.801 & 0 & 3.801 & 0 & 3.801 & 0.468 & $\mid 0$ & 0 & 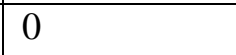 & 0 & 0 & 0 \\
\hline C15 & 4.098 & 0.344 & 3.755 & 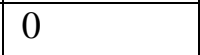 & 3.754 & 0 & 3.754 & 0 & 3.754 & 0.344 & 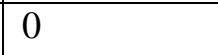 & 0 & \begin{tabular}{|l|l|} 
\\
\end{tabular} & 0 & 0 & 0 \\
\hline C16 & 3.934 & 0.242 & 3.692 & 0 & 3.692 & 0 & 3.691 & 0 & 3.691 & 0.243 & 0 & 0 & 0 & 0 & 0 & 0 \\
\hline C17 & 3.777 & 0.184 & 3.593 & 0 & 3.593 & 0 & 3.592 & 0 & 3.592 & 0.184 & 0 & 0 & 0 & 0 & 0 & 0 \\
\hline C18 & 3.626 & \begin{tabular}{|l|l|}
0.136 \\
\end{tabular} & 3.490 & 0 & 3.490 & 0 & 3.489 & 0 & 3.489 & 0.136 & 0 & 0 & 0 & 0 & 0 & 0 \\
\hline C19 & 3.481 & 0.099 & 3.381 & 0 & 3.381 & 0 & 3.381 & 0 & 3.381 & 0.100 & 0 & 0 & 0 & 0 & 0 & 0 \\
\hline $\mathbf{C 2 0}$ & 3.341 & \begin{tabular}{|l|l}
0.071 \\
\end{tabular} & 3.271 & \begin{tabular}{|l|l} 
\\
\end{tabular} & $\mid 3.271$ & 0 & 3.271 & 0 & 3.271 & 0.071 & \begin{tabular}{|l|l} 
\\
\end{tabular} & 0 & \begin{tabular}{|l|l} 
\\
\end{tabular} & 0 & 0 & 0 \\
\hline C21 & 3.208 & 0.051 & 3.157 & 0 & 3.157 & 0 & 3.157 & 0 & 3.157 & 0.051 & 0 & 0 & 0 & 0 & 0 & 0 \\
\hline $\mathbf{C 2 2}$ & 3.079 & 0.038 & 3.042 & 0 & 3.042 & 0 & 3.042 & 0 & 3.042 & 0.038 & 0 & 0 & 0 & 0 & 0 & 0 \\
\hline $\mathbf{C 2 3}$ & 2.956 & 0.026 & 2.930 & 0 & 2.930 & 0 & 2.930 & 0 & 2.930 & 0.026 & 0 & 0 & 0 & 0 & 0 & 0 \\
\hline C24 & 2.838 & 0.019 & 2.819 & \begin{tabular}{|l|l|} 
\\
\end{tabular} & 2.819 & 0 & 2.819 & 0 & 2.819 & 0.019 & \begin{tabular}{|l|l|} 
\\
\end{tabular} & 0 & \begin{tabular}{|l|l|} 
\\
\end{tabular} & 0 & 0 & 0 \\
\hline C25 & 2.725 & 0.013 & 2.711 & 0 & 2.711 & 0 & 2.711 & 0 & 2.711 & 0.013 & 0 & 0 & 0 & 0 & 0 & 0 \\
\hline $\mathbf{C 2 6}$ & 2.616 & 0.009 & 2.606 & $\mid 0$ & 2.606 & 0 & 2.606 & 0 & 2.606 & 0.009 & $\mid 0$ & 0 & $\mid 0$ & 0 & 0 & 0 \\
\hline $\mathbf{C 2 7}$ & 2.511 & 0.006 & 2.505 & 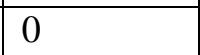 & 2.505 & 0 & 2.505 & 0 & 2.505 & 0.006 & 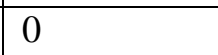 & 0 & 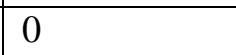 & 0 & 0 & 0 \\
\hline $\mathbf{C 2 8}$ & 2.410 & 0.005 & 2.406 & 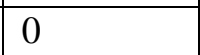 & 2.406 & 0 & 2.406 & 0 & 2.406 & 0.005 & 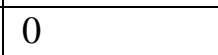 & 0 & 0 & 0 & 0 & 0 \\
\hline $\mathbf{C 2 9}$ & 2.314 & 0.003 & 2.311 & 0 & 2.311 & 0 & 2.311 & 0 & 2.311 & 0.003 & 0 & 0 & 0 & 0 & 0 & 0 \\
\hline C30 & 99.97 & 0.108 & 99.86 & $\mid$\begin{tabular}{|l|l|} 
\\
\end{tabular} & 99.86 & 0 & 99.86 & 0 & 99.86 & 0.108 & $\mid$\begin{tabular}{|l|l|} 
\\
\end{tabular} & 0 & $\mid$\begin{tabular}{|l|l|} 
\\
\end{tabular} & 0 & 0 & 0 \\
\hline
\end{tabular}




\begin{tabular}{|c|c|c|c|c|c|c|c|c|c|c|c|c|c|c|c|c|}
\hline $\begin{array}{l}\text { Total Flow } \\
\text { (kmol/hr) }\end{array}$ & 63,980 & 35,573 & 28410 & 1.198 & 28,409 & 106.4 & 28,302 & 28,125 & 176.8 & 49,890 & 4,393 & 10.72 & 4,749 & 38.22 & 4,622 & 103.5 \\
\hline $\begin{array}{l}\text { Total Flow } \\
\text { (kg/hr) }\end{array}$ & $4.895 * 10^{6}$ & $2.41 * 10^{6}$ & $2.49 * 10^{6}$ & 84.47 & $2.49 * 10^{6}$ & 7,830 & $2.48 * 10^{6}$ & $2.42 * 10^{6}$ & 60,581 & $4.30^{*} 10^{6}$ & 37,318 & 194.8 & $4.02 * 10^{5}$ & 1,106 & 84,476 & 8,812 \\
\hline $\begin{array}{l}\text { Temperatu } \\
\text { re }\left({ }^{\circ} \mathrm{C}\right)\end{array}$ & 240 & 200 & 200 & 200 & 200 & 200 & 200 & 130.5 & 492.7 & 132.6 & 5 & 5 & 5 & 5 & 5 & 5 \\
\hline $\begin{array}{l}\text { Pressure } \\
\text { (bar) }\end{array}$ & 45 & 45 & 45 & 35 & 35 & 30 & 30 & 5 & 7.9 & 5.203 & 15 & 15 & 5 & 5 & 5 & 15 \\
\hline Vapor Frac & 0.988 & 1 & 0 & 1 & 0 & 1 & 0 & 1 & 0 & 0 & 1 & 0 & 0 & 1 & 0 & 0 \\
\hline $\begin{array}{l}\text { Liquid } \\
\text { Frac }\end{array}$ & 0.012 & 0 & 1 & 0 & 1 & 0 & 1 & 0 & 1 & 1 & 0 & 1 & 1 & 0 & 1 & 1 \\
\hline
\end{tabular}


Appendix D: Scenario 2 Simulation Stream Results

The table below tabulates the stream results that were obtained from running the Aspen Plus simulation for Scenario 2.

\begin{tabular}{|c|c|c|c|c|c|c|c|c|c|c|c|c|}
\hline Mole Flow (kmol/hr) & FTPROD & CFTPROD & VAPOR1 & HC & WATER1 & LPVAPOR1 & CVAPOR1 & SYNGAS & SOLVENT1 & WATER2 & VAPOR2 & HEAVY \\
\hline $\mathrm{CO}$ & 1244 & 1244 & 1022 & 208.3 & 14.32 & 1022 & 1022 & 1012 & 6.323 & 2.923 & 208.3 & 0 \\
\hline H2 & 3355 & 3355 & 3355 & 0.046 & 0.003 & 3355 & 3355 & 3355 & 0 & 0 & 0.046 & 0 \\
\hline H2O & 4536 & 4536 & 389.4 & 267.6 & 3879 & 389.4 & 389.4 & 46.15 & 2.307 & 341.0 & 267.6 & 0 \\
\hline C1 & 7.257 & 7.257 & 3.111 & 3.880 & 0.267 & 3.111 & 3.111 & 2.916 & 0.133 & 0.062 & 3.880 & 0 \\
\hline $\mathrm{C} 2$ & 6.967 & 6.967 & 0.889 & 5.687 & 0.391 & 0.889 & 0.889 & 0.745 & 0.098 & 0.046 & 5.687 & 0 \\
\hline $\mathrm{C3}$ & 6.689 & 6.689 & 0.560 & 5.734 & 0.394 & 0.560 & 0.560 & 0.405 & 0.106 & 0.049 & 5.734 & 0 \\
\hline C4 & 6.421 & 6.421 & 0.341 & 5.680 & 0.400 & 0.341 & 0.341 & 0.175 & 0.113 & 0.053 & 5.680 & 0 \\
\hline C5 & 6.164 & 6.164 & 0.185 & 5.979 & 0 & 0.185 & 0.185 & 0.069 & 0.116 & 0 & 5.979 & 0 \\
\hline C6 & 54,630 & 54,630 & 887.6 & 53,740 & 0.400 & 887.6 & 887.6 & 178.5 & 709.1 & 0.013 & 53,740 & 0.156 \\
\hline C8 & 5.454 & 5.454 & 0.017 & 5.437 & 0 & 0.017 & 0.017 & 0 & 0.016 & 0 & 0 & 5.437 \\
\hline C9 & 5.235 & 5.235 & 0.013 & 5.222 & 0 & 0.013 & 0.013 & 0 & 0.012 & 0 & 0 & 5.222 \\
\hline C10 & 5.026 & 5.026 & 0.007 & 5.019 & 0 & 0.007 & 0.007 & 0 & 0.006 & 0 & 0 & 5.019 \\
\hline C11 & 4.825 & 4.825 & 0.003 & 4.822 & 0 & 0.003 & 0.003 & 0 & 0.003 & 0 & 0 & 4.822 \\
\hline C12 & 4.632 & 4.632 & 0.002 & 4.630 & 0 & 0.002 & 0.002 & 0 & 0.002 & 0 & 0 & 4.630 \\
\hline C13 & 4.447 & 4.447 & 0 & 4.446 & 0 & 0 & 0 & 0 & 0 & 0 & 0 & 4.446 \\
\hline C14 & 4.269 & 4.269 & 0 & 4.268 & 0 & 0 & 0 & 0 & 0 & 0 & 0 & 4.268 \\
\hline C15 & 4.098 & 4.098 & 0 & 3.834 & 0.264 & 0 & 0 & 0 & 0 & 0 & 0 & 3.834 \\
\hline C16 & \begin{tabular}{|l|l|}
3.934 \\
\end{tabular} & 3.934 & 0 & 3.934 & 0 & 0 & 0 & 0 & 0 & 0 & 0 & 3.934 \\
\hline C19 & 3.481 & 3.481 & 0 & 3.257 & 0.224 & 0 & 0 & 0 & 0 & 0 & 0 & 3.257 \\
\hline C20 & \begin{tabular}{|l|l|}
3.341 \\
\end{tabular} & 3.341 & 0 & 3.127 & 0.215 & 0 & 0 & 0 & 0 & 0 & 0 & 3.127 \\
\hline C21 & 3.208 & 3.208 & 0 & 3.002 & 0.206 & 0 & 0 & 0 & 0 & 0 & 0 & 3.002 \\
\hline $\mathrm{C} 22$ & 3.079 & 3.079 & 0 & 2.881 & 0.198 & 0 & 0 & 0 & 0 & 0 & 0 & 2.881 \\
\hline $\mathrm{C23}$ & 2.956 & 2.956 & 0 & 2.766 & 0.190 & 0 & 0 & 0 & 0 & 0 & 0 & 2.766 \\
\hline C24 & 2.838 & 2.838 & 0 & 2.656 & 0.183 & 0 & 0 & 0 & 0 & 0 & 0 & 2.656 \\
\hline $\mathbf{C 2 5}$ & 2.725 & 2.725 & 0 & 2.549 & 0.175 & 0 & 0 & 0 & 0 & 0 & 0 & 2.549 \\
\hline $\mathrm{C26}$ & 2.616 & 2.616 & 0 & 2.447 & 0.168 & 0 & 0 & 0 & 0 & 0 & 0 & 2.447 \\
\hline C27 & 2.511 & 2.511 & 0 & 2.349 & 0.162 & 0 & 0 & 0 & 0 & 0 & 0 & 2.349 \\
\hline C28 & 2.410 & 2.410 & 0 & 2.255 & 0.155 & 0 & 0 & 0 & 0 & 0 & 0 & 2.255 \\
\hline C29 & 2.314 & 2.314 & 0 & 2.165 & 0.149 & 0 & 0 & 0 & 0 & 0 & 0 & 2.165 \\
\hline $\mathbf{C 3 0}$ & \begin{tabular}{|l|l}
99.97 \\
\end{tabular} & 99.97 & 0 & 93.51 & 6.429 & 0 & 0 & 0 & 0 & 0 & 0 & 93.54 \\
\hline Total Flow (kmol/hr) & 63,980 & 63,980 & 5,659 & 54,420 & 3904 & 5659 & 5659 & 4597 & 718.3 & 344.1 & 54,240 & 177 \\
\hline
\end{tabular}


Total Flow (kg/hr)

Temperature $\left({ }^{\circ} \mathrm{C}\right)$

\begin{tabular}{|l|l|l}
$4.895 * 10^{6}$ & $4.895 * 10^{6}$ & $1.190 * 10^{5}$
\end{tabular}

\begin{tabular}{|l|l}
$4.702 * 10^{6}$ & 73,940 \\
\hline
\end{tabular}

$1.190 * 10^{5}$

$1.190 * 10^{5}$

240

$4.895^{*} 10^{6}$

1.190

\begin{tabular}{|l|l|l|l|l|l}
\hline 125 & 125 & 125 & 125 & 123.3 \\
45 & 40 & 40 & 40 & 30 \\
\hline
\end{tabular}

Pressure (bar)

0.988

Vapor Frac

Liquid Frac

0.012

0.867

\begin{tabular}{|l|l|l|}
0 & 0 & 1 \\
\hline 1 & 1 & 0
\end{tabular}

\begin{tabular}{l|l}
1.10 \\
30 & 30 \\
\hline & 0.876 \\
\hline
\end{tabular}

\begin{tabular}{l|l}
70 & 70 \\
\hline 30 & 35
\end{tabular}

0

0.124

1

\begin{tabular}{|l|l|l|l|}
\hline 61,360 & 6233 & $4.643^{*} 10^{6}$ & 58,540 \\
\hline 70 & 70 & 130.2 & 414.7 \\
\hline 35 & 35 & 5 & 5.221 \\
\hline 0 & 0 & 1 & 0 \\
\hline 1 & 1 & 0 & 1 \\
\hline
\end{tabular}


Appendix E: Scenario 3 Simulation Stream Results

The table shows the Aspen Plus simulation stream results obtained for Scenario 3.

\begin{tabular}{|c|c|c|c|c|c|c|c|c|c|c|}
\hline Mole Flow (kmol/hr) & FTPROD & VFTPROD & LFTPROD & SYNGAS & $\mathrm{HC}$ & WATER & SOLVENT+ & C7-C13 & MIDDIST & C30+ \\
\hline $\mathrm{CO}$ & 1,244 & 1,244 & 0 & 807.0 & 406.2 & 30.96 & 406.2 & 0 & 0 & 0 \\
\hline H2 & 3,355 & 3,355 & 0 & 3,355 & 0.015 & 0.001 & 0.015 & 0 & 0 & 0 \\
\hline $\mathrm{H2O}$ & 4,536 & 4,536 & 0 & 43.80 & 173.7 & 4,318 & 173.7 & 0 & 0 & 0 \\
\hline C1 & 7.257 & 7.257 & 0 & 1.461 & 5.386 & 0.411 & 5.386 & 0 & 0 & 0 \\
\hline $\mathbf{C 2}$ & 6.967 & 6.967 & 0 & 0.558 & 5.955 & 0.454 & 5.955 & 0 & 0 & 0 \\
\hline $\mathbf{C 3}$ & 6.688 & 6.688 & 0 & 0.280 & 5.954 & 0.454 & 5.954 & 0 & 0 & 0 \\
\hline $\mathrm{C4}$ & 6.421 & 6.421 & 0 & 0.111 & 5.857 & 0.452 & 5.857 & 0 & 0 & 0 \\
\hline C5 & 6.164 & 6.164 & 0 & 0.045 & 6.119 & 0 & 6.119 & 0 & 0 & 0 \\
\hline C6 & 54,628 & 54,628 & 0 & 168.3 & 54459 & 0.146 & 54,459 & 0 & 0 & 0 \\
\hline C7 & 5.681 & 5.681 & 0 & 0.007 & 5.674 & 0 & 0 & 5.674 & 0 & 0 \\
\hline C8 & 5.454 & 5.454 & 0 & 0.002 & 5.451 & 0 & 0 & 5.451 & 0 & 0 \\
\hline C9 & 5.235 & 5.235 & 0 & 0.001 & 5.234 & 0 & 0 & 5.234 & 0 & 0 \\
\hline C10 & 5.026 & 5.026 & 0 & 0 & 5.026 & 0 & 0 & 5.026 & 0 & 0 \\
\hline C11 & 4.825 & 4.825 & 0 & 0 & 4.825 & 0 & 0 & 4.825 & 0 & 0 \\
\hline C12 & 4.632 & 4.632 & 0 & 0 & 4.632 & 0 & 0 & 4.632 & 0 & 0 \\
\hline $\mathbf{C 1 3}$ & 4.447 & 4.447 & 0 & 0 & 4.447 & 0 & 0 & 4.447 & 0 & 0 \\
\hline C14 & 4.269 & 0 & 4.269 & 0 & 0 & 0 & 0 & 0 & 4.269 & 0 \\
\hline C15 & 4.098 & 0 & 4.098 & 0 & 0 & 0 & 0 & 0 & 4.098 & 0 \\
\hline C16 & 3.934 & 0 & 3.934 & 0 & 0 & 0 & 0 & 0 & 3.934 & 0 \\
\hline C17 & 3.777 & 0 & 3.777 & 0 & 0 & 0 & 0 & 0 & 3.777 & 0 \\
\hline C18 & 3.626 & 0 & 3.626 & 0 & 0 & 0 & 0 & 0 & 3.626 & 0 \\
\hline C19 & 3.481 & 0 & 3.481 & 0 & 0 & 0 & 0 & 0 & 3.480 & 0 \\
\hline C20 & 3.341 & 0 & 3.341 & 0 & 0 & 0 & 0 & 0 & 3.340 & 0.001 \\
\hline C21 & 3.208 & 0 & 3.208 & 0 & 0 & 0 & 0 & 0 & 3.205 & 0.003 \\
\hline
\end{tabular}




\begin{tabular}{|c|c|c|c|c|c|c|c|c|c|c|}
\hline C22 & 3.079 & 0 & 3.079 & 0 & 0 & 0 & 0 & 0 & 3.073 & 0.007 \\
\hline $\mathbf{C 2 3}$ & 2.956 & 0 & 2.956 & 0 & 0 & 0 & 0 & 0 & 2.940 & 0.016 \\
\hline $\mathbf{C 2 4}$ & 2.838 & 0 & 2.838 & 0 & 0 & 0 & 0 & 0 & 2.801 & 0.037 \\
\hline $\mathbf{C 2 5}$ & 2.725 & 0 & 2.725 & 0 & 0 & 0 & 0 & 0 & 2.634 & 0.091 \\
\hline C26 & 2.616 & 0 & 2.616 & 0 & 0 & 0 & 0 & 0 & 2.355 & 0.260 \\
\hline $\mathbf{C 2 7}$ & 2.511 & 0 & 2.511 & 0 & 0 & 0 & 0 & 0 & 1.793 & 0.718 \\
\hline C28 & 2.410 & 0 & 2.410 & 0 & 0 & 0 & 0 & 0 & 0.958 & 1.452 \\
\hline $\mathbf{C 2 9}$ & 2.314 & 0 & 2.314 & 0 & 0 & 0 & 0 & 0 & 0.283 & 2.031 \\
\hline $\mathbf{C 3 0}$ & 99.97 & 0 & 99.97 & 0 & 0 & 0 & 0 & 0 & 4.585 & 95.38 \\
\hline Total Flow $\mathrm{kmol} / \mathrm{hr}$ & 63,983 & 63,832 & 151.2 & 4,377 & 55,104 & 4,351 & 55,068 & 35.29 & 51.15 & 100 \\
\hline Total Flow $\mathrm{kg} / \mathrm{hr}$ & $4.89 * 10^{6}$ & $4.84 * 10^{6}$ & 57,189 & 44,728 & $4.71 * 10^{6}$ & 78,744 & $4.71 * 10^{6}$ & 4,941 & 15,033 & 42,156 \\
\hline Temperature $\mathrm{C}$ & 240 & 240 & 240 & 70 & 70 & 70 & 40 & 40 & 469.3 & 540.4 \\
\hline Pressure bar & 45 & 45 & 45 & 35 & 35 & 35 & 30 & 30 & 5 & 5 \\
\hline Vapor Frac & 0.988 & 1 & 0 & 1 & 0 & 0 & 0 & 0 & 1 & 0 \\
\hline Liquid Frac & 0.012 & 0 & 1 & 0 & 1 & 1 & 1 & 1 & 0 & 1 \\
\hline
\end{tabular}

